Hope College

Hope College Digital Commons

Faculty Publications

$9-2016$

\title{
Is This Relevant? Physician Perceptions, Clinical Relevance, and Religious Content in Clinical Interactions
}

Aaron B. Franzen

franzen@hope.edu, franzen@hope.edu

Follow this and additional works at: https://digitalcommons.hope.edu/faculty_publications

Part of the Medicine and Health Commons

\section{Recommended Citation}

Franzen, A. B. (2016), Is This Relevant? Physician Perceptions, Clinical Relevance, and Religious Content in Clinical Interactions. JOURNAL FOR THE SCIENTIFIC STUDY OF RELIGION, 55: 438-464. doi:10.1111/ jssr.12289

This Article is brought to you for free and open access by Hope College Digital Commons. It has been accepted for inclusion in Faculty Publications by an authorized administrator of Hope College Digital Commons. For more information, please contact digitalcommons@hope.edu. 


\title{
Is this Relevant?: \\ Physician Perceptions, Clinical Relevance, and Religious Content in Clinical Interactions
}

\author{
Aaron B. Franzen, Ph.D. \\ Hope College
}

2016

*** Accepted and forthcoming in the Journal for the Scientific Study of Religion. ***

\begin{abstract}
Despite wide support among physicians for practicing patient-centered care, clinical interactions are primarily driven by physicians' perception of relevance. These perceptions of relevance depend on the physician's own biographical background. While some physicians will perceive a connection between religion and patient health, this relevance will be less apparent for others. I argue here that physician responses when religious/spiritual topics come up during clinical interactions will depend on their own religious/spiritual background. The more central religion is for the physician, as reflected by their religious/spiritual orientation, intrinsic religiosity, and religious coping, the greater their perception of religion's impact on health outcomes and their inclusion of religion/spirituality within clinical interactions. Using a nationally representative sample of physicians in the U.S. and mediated path models, I estimate models for five different physician actions to evaluate these relationships. I find that a physician's religious background is strongly associated with whether or not they think religion impacts health outcomes, which is strongly predictive of inclusion. I also find that not all of the association between inclusion and physicians' religious background is mediated by thinking religion impacts health outcomes. Issues of religion's relevance for medicine are important to the degree that religious beliefs are an important dimension of patients' lives.
\end{abstract}

Running head: Is This Relevant?

Keywords: Patient interactions; physician beliefs; clinical interactions; path modeling; professional values

Contact information - email: Franzen@hope.edu 


\section{Is this Relevant?: Physician Perceptions, Clinical Relevance, and Religious Content in Clinical Interactions}

Who decides what is relevant in a conversation between a physician and patient? Is anything the patient wants to talk about or share with the physician fair game? Or is it the physician's role to direct the conversation toward what he or she sees as medically relevant? Most often it is the latter, and in the process, the physician’s decision may actually bypass patient-centered care.

Problems arise when patients want something different from the interaction with their physician. Toombs (1987) argues that patients almost universally understand their illnesses in terms of their everyday life while physicians tend to think of illnesses in terms of physical indicators with a named diagnosis and specific treatment. When patients and physicians talk about illness, they tend to be referencing different realities. If the gap between these realities is large enough, a failure in health care can occur (Toombs 1987).

While both parties have a role to play during clinical conversations, both the physician's and patient's identity are biographically constrained, which means that out of each identity flows perhaps differing perceptions of conversational relevance. While ill patients understand their illness in terms of their everyday lives, they also have some idea of what information their physician expects them to share. What patients think they should share and what the physician wants them to share, however, is not always the same. Dubbin, Chang, and Shim (2013) find that even when physicians seek to practice patient-centered care, they still have strong perceptions of what is relevant in any given conversation with patients, and patients do not always have the ability or background to live up to these expectations. The problem is that what physicians see as relevant may not always be in line with what the patient needs for best care. Patient-centered 
care is defined by the physician's ability to get a feeling for who the patient is as a person, in addition to diagnosing the patient's physical ailment and designing a treatment with a good prognosis of success (Mead and Bower 2000).

Many patients want their physicians to ask about or at least be aware of their religious beliefs (Bernard, Quill, and Tulsky 1999; Ehman et al. 1999; King and Bushwick 1994; Koenig et al. 1991; MacLean et al. 2003; Phelps et al. 2012; Wexler and Corn 2012; Williams et al. 2011; Winkelman et al. 2011), but this rarely takes place (Cadge, Calle, and Dillinger 2011; Koenig et al. 1991; Williams et al. 2011). The physician’s propensity to take into account a patient's religious beliefs will tend to vary not just according to the patient's beliefs but also according to the physician's own religious/spiritual orientation, intrinsic religiosity, and centrality of religion for making sense of life. This study compares the physicians’ religious/spiritual backgrounds with how they respond when religious topics come up in clinical interactions. The purpose is to begin building a construct to make sense of how personal beliefs and values change, shift, and merge with professional beliefs and values. Specifically, I argue that the more central religion is to the physician, the more likely he or she is to have connected these personal beliefs to the profession of healing patients. Those physicians who think religion matters for the health of patients will include religion/spirituality in their interactions with them more often than will physicians who do not see this connection. Using a nationally representative sample of physicians and five different mediated path models predicting physician actions, I find that thinking religion impacts patients’ health does mediate the relationship between physicians’ religious/spiritual backgrounds and their clinical practices. Physicians’ beliefs include beliefs about the impact of religion on patient health, which is then related to their actions in clinical settings. 


\section{BACKGROUND}

\section{Patient-Centered Care}

While modern, science-based, Western medicine has been criticized for its tendency to focus on biological processes of illness at the expense of a holistic patient-focused approach (Engel 1977, 1980; Toombs 1990), recent years have seen an increased call in the medical community for the practice of patient-centered care (Kitson et al. 2013; McWhinney 1993; Stewart 1995, 2001). Significant organizations, such as the National Health Service, the U.S. Department of Health and Human Services (Dubbin et al. 2013), and the World Health Organization (2000), have also pushed for medical practice to be more centered on the patient. This heightened focus underlines the relevance of the present study, which posits that physicians differ from one another and that these differences lead to clear-cut variations in their perceptions of what is relevant for medicine and, as a result, for the provision of patient-centered care. Particularly in the case of including religion/spirituality in patient interactions, these differences in the perceived relevance of religion/spirituality for medical care is socially patterned according to the physician’s own religiosity.

While there is some confusion over what patient-centered care implies for policy changes and advances in medical education, widespread support is rising for the philosophy that supports this approach to patient care (Kitson et al. 2013). For some, this means having sympathy but not empathy for patients (Macnaughton 2009). Others more recently argued that being willing to emphasize subjective connections instead of objectified connections with patients is key (Carel and Macnaughton 2012). Epstein et al. (2005) define patient-centered care as actions flowing from a certain moral philosophy, generally defined by an interest in caring for the patient's cultural values, needs, and preferences. Three core values make up this moral philosophy 
(Epstein et al. 2005), two of which are pertinent here. First, a patient should be treated as an individual with experiences, not merely a biological host for some illness or a living example of a list of clinical indicators (Dubbin et al. 2013; Mead and Bower 2000). Second, the physician should make an attempt to understand the perspective of the patient so that the two can come to a shared understanding of the illness, the plan of treatment, and the impact on the patient's life (Epstein et al. 2005; Halpern 2001; Toombs 1987).

As Kitson et al. (2013) point out, while there is near unanimous agreement in the philosophical approach undergirding patient-centered care, there is rarely agreement on what this means clinically. Similarly, in a qualitative study, Dubbin, Chang, and Sim (2013) find that it may be challenging for a physician to live up to the lofty goal of patient-centered care. Quite often patients did not have what Dubbin, Chang, and Sim refer to as the "cultural health capital” to successfully provide the clinical goods expected by their physician. This means that while physicians may agree they should pursue patient-centered care, their own cultural background shapes what they perceive as relevant and irrelevant for clinical interactions. In other words, it can be a challenge for any physician to really practice patient-centered care because the physician’s perception of relevance always directs patient interactions.

Toombs (1987) persuasively made a similar argument from a phenomenological perspective. She argued that everything becomes what it is to us by focusing on one dimension or another of any given object or experience. Following Schutz (1962a, 1962b), she then argues that what anyone focuses on in a given situation will depend on their biographical background, and medical interactions and illness are no different. Because the physician tends to focus on illnesses as a disease process while the patient tends to focus on illness in the terms of everyday life, potentially little overlap occurs in terms of the patient's and the physician's horizons of 
meaning. To put this another way, the two may struggle to connect with one another because although they are conversing about one thing — an illness — that single illness is literally two different realities — the disease process inferred by the physician and the disrupted everyday life of the patient.

This difference between the illness confronted by the physician and the illness experienced by the patient is why patient-centered care is so important. Significantly, physicians tend to have the most success helping patients make sense of their illness and facilitate their path back towards health when patient experiences are taken into account in medical interactions (Frank 1991; MacIntyre 1977). Because patients make sense of sickness through the context of their biographical background, it should not be surprising that many patients want their religious beliefs to be at least some part of their health care (Koenig et al. 1991; Williams et al. 2011).

Just as physicians’ cultural backgrounds direct perceptions of clinical relevance (Dubbin et al. 2013), physician reactions to the presence of religious content in clinical situations will not be the same for all physicians.

\section{Physician Religiosity/Spirituality and Medical Interactions}

Four-part Religious/Spiritual Typology. When considering differing physician perspectives regarding the relevance of religion for clinical interactions, a physician's own religious orientation, intrinsic religiosity, and religious coping is important. As demonstrated in an earlier study (Franzen 2014), individual religious/spiritual orientations_-such as claiming to be “religious and spiritual,” “spiritual but not religious,” "religious but not spiritual,” and "not religious or spiritual” (hereafter RAS, SBNR, RBNS, and NROS)—are in some ways more helpful than other measures (for instance, congregational attendance rates) for gauging such social processes as physician-patient interactions. In line with theoretical relationships and 
implications outlined by Jang and Franzen (2013), these orientations relate to medical interactions and are helpful for two reasons. First, religiosity and spirituality correlate with fairly distinct ways of believing and how those beliefs connect with day-to-day life. Are religious beliefs all-encompassing for reality, or are they highly peripheral and easily compartmentalized or ignored? Are they best reflected in organizational or communal practices and statements of faith, or are they best reflected in an individualized and personal pursuit of the transcendent? Second, separating self-identified spiritual or religious orientations in this way also allows researchers to differentiate individuals who are spiritual but not antagonistic towards communal or organized religious practices from those who are spiritual but opposed to organized and communal expressions of belief.

These "religious" and "spiritual” typological categories tend to follow certain social patterns of belief and behavior. On one hand, the religious dimension tends to relate to beliefs and practices that are communally and organizationally based, tradition and creed-oriented, and associated with institutional and social pressures (Pepper, Jackson, and Uzzell 2010; Piedmont 1999; Saucier and Skrzypinska 2006; Schlehofer, Omoto, and Adelman 2008; Wink et al. 2007; Wink and Dillon 2003; Zinnbauer et al. 1997; Zwissler 2007). The spiritual dimension, on the other hand, generally relates to an individual's subjective beliefs and pursuits, is often characterized by a propensity for "spiritual seeking" and personal experiences, includes nontheistic ideas of a higher power and an interest in unorthodox beliefs and practices, and may cooccur with negative feelings towards organized forms of religion (Fuller 2001; Jang and Franzen 2013; Piedmont 1999; Roof 1993; Saucier and Skrzypinska 2006; Schlehofer, Omoto, and Adelman 2008; Wink and Dillon 2003; Wuthnow 1998; Zinnbauer et al. 1997). 
This four-part typology is effective but denies, or at least largely downplays, some of the variation that exists when it comes to how religiosity affects the rest of an individual's life. This missing element is largely what is captured by measures of intrinsic religiosity (Hoge 1972). Intrinsic religiosity is not a measure of behavior but is a measure of motivation related to "personal religion" (Cohen and Hill 2007) that then tends to be associated with behaviors. More simply put, it drives action. It is a useful addition to religious/spiritual orientations because it helps us differentiate this internal motivation from some of the more structural connotations that distinguish some of the religious/spiritual typological categories.

Religious Coping and Medical Socialization/Practice. A key dimension of religion for Weber (1993) was theodicy, its ability to recreate meaning in the face of suffering, loss or pain. This ability to explain and cope with human suffering is relevant for medicine and medical socialization, as demonstrated by Balboni et al. (2015) who show that religious medical students appear to be better equipped or to have more resources than the non-religious to deal with the suffering and challenges they face, a point Curlin et al. (2005) also verified for practicing physicians. One reason that religious coping may be important for our purposes here is that religion provides additional resources for physicians precisely because it can be the filter through which all of life falls, providing continuity and meaning for the flow of experiences (Berger 1990).

If a key buttressing force for medicine’s present power and authority is the nearly unmitigated deployment of science (Light 2004; Porter 1993; Starr 1982), then we would expect a concurrent reduction of the "personal" in medical interactions— in favor of "just the facts" (Engel 1977, 1980; Toombs 1987). If religion is a strong piece of the physician's personal life, however, his or her view of the world could be problematic for or in conflict with their 
professional socialization as a physician. Indeed, identity struggles can be more prominent for medical students who are religious/spiritual as compared with those who are not (Balboni et al. 2015). In fact, Catlin et al. (2008) find that pediatricians have diminished religiosity compared to when they were younger, and they speculate that professional socialization could be one potential cause for this decrease. Interestingly enough, Balboni et al. (2015) also find that nonreligious medical students are more prone to compartmentalizing professional experiences, erecting a sort of cognitive and emotional partition from the rest of their life. This experience of medical socialization fits with the ideas outlined above regarding the universalizing meaningmaking role of religion in some physicians' lives, which could counter such compartmentalizing. How physicians cognitively connect their beliefs and professional work will matter for their patient interactions. Chatters (2000), following work started by Pargament (1997), outlines four different cognitive connections between religion and medicine: rejectionism, exclusivism, constructivism, and pluralism. Cadge and Ecklund (2009) propose similar constructs from interviews with pediatric oncologists about their response when asked by a patient or family to pray with them: participate in prayer with them, accommodate their request but not participate, reframe requests (e.g., Family: “will you pray for ....”; Physician: “everyone will pray for ...”), and re-direct the request to the family's pastor or the chaplain. Even though the boundaries between these constructs are likely to be porous, we can use them to begin to make sense of different cognitive connections between personal beliefs/values and professional beliefs/values.

Whether or not one's personal beliefs and values cross cognitive domains and impact professional role perceptions, beliefs, and values would likely depend on whether the personal beliefs are "deep” or "shallow” schemes (Johnson-Hanks et al. 2011). If the religious beliefs are deeper and more universal in terms of the individual's worldview, then they are much more 
likely to be interwoven with his or her profession. The degree to which this has happened is also the degree to which the individual is likely to perceive the relevance of the one (religion) for the other (medical practice). It should be mentioned that training specifically targeted at spiritual care could also shift perceptions of relevance, as training is a key reason physicians provide or do not provide spiritual care, at least when it comes to end-of-life care (Balboni et al. 2012). Whether a single continuum of relevance and irrelevance of religion for one's medical practice exists or whether there are instead somewhat clear categories, such as those Chatters (2000) or Cadge and Ecklund (2009) defined, has yet to be shown, but we gain much by uncovering initial relationships between personal beliefs and orientations, especially with regard to perceptions of religion's relevance for medicine and clinical practice.

Religious and Spiritual (RAS) and Spiritual But Not Religious (SBNR). We can, to begin with, outline here some expectations based on literature outlined thus far. RAS individuals will be personally invested in their beliefs, but these beliefs tend to be communally-tied affirmations. This will imbue their beliefs with a more universal ontological position: it applies to all things and all people whether or not they also believe because the beliefs reflect something that is "real.” This orientation presents a potential problem for RAS physicians because medicine is a scientific profession, often overlooking or regarding religious beliefs as irrelevant. This conflict between a deeply belief-informed worldview and their chosen profession will force more reflection than may otherwise be the case, creating a clearer connection between their beliefs and their profession if the belief-set is retained. In fact, Grossoehme et al. (2007) show that very religious and spiritual Christian pediatricians talk with patients more than other pediatricians about their own beliefs and practices as well as pray with them. 
SBNR individuals, on the other hand, are personally invested in some belief, but the beliefs tend to be more individualistic, given that they shy away from creeds, formal statements of faith, and faith communities. There may also be decreased pressure for SBNR physicians to figure out how their own beliefs map onto their profession since their beliefs lack that universal quality. As a result, their inclusion of religious topics within medical interactions may not necessarily be the result of the relevance of their beliefs mapped onto their medical practice, as is likely the case for the RAS physicians.

If it is true that intrinsic religiosity is itself a religious motivational orientation for action (Hoge 1972), then it should generally be related to increased relevance of religion for medicine and increased inclusion in clinical conversations. Related to this point, if intrinsic religiosity is primarily capturing personal religiosity/religion (Cohen and Hill 2007), then it will likely account for much of the differences between the RAS and SBNR respondents in terms of religion's relevance for medicine and their resulting actions. The same is likely true for religious coping, as the more one uses religious tools to make sense of experiences, the more influential and relevant that specific schema is for other domains of one's life.

Religious But Not Spiritual (RBNS) and Not Religious or Spiritual (NROS). There are fewer RBNS individuals than other religious/spiritual categories in the United States (Dougherty and Jang 2008), and even fewer physicians tend to identify as "religious” than the general population (Catlin et al. 2008). The religious schema for RBNS individuals may be shallower in the sense that it is more domain-specific. They may go to church and retain traditions, but those practices are contextualized within "religious" settings; people "do" religion in a different place than they "do" medicine. This also means that religion is likely not the primary frame by which they make sense of their reality since it does not undergird all of their life but occupies only one 
dimension. NROS individuals would be the most prone to reject and redirect any religious content because religion is not an interpretive lens in their own life and is therefore least relevant for medical practice compared to other orientations for them. Because religious or spiritual beliefs are not central for making sense of their experiences, they will tend to overlook the role religion may play in their patients' health.

\section{DATA AND METHODS}

The data for this study comes from two different sources. First, data about physician religious/spiritual orientations and beliefs as well as their patient interactions is from the Religion and Spirituality in Medicine: Physicians’ Perspectives (RSMPP) survey. The RSMPP covers physicians’ religious beliefs, patient interactions, and views regarding the role of religion in medicine (see Curlin et al. 2005, 2006, 2007). The survey sample was a stratified random sample of 2,000 physicians from the American Medical Association Physician Masterfile age 65 and younger. The sample was stratified by physician specialty so as to oversample some medical specialties such as geriatrics, pediatric specialties, pulmonary, critical care, and psychiatry (Curlin et al. 2005). The survey was a mailed, self-administered questionnaire sent out in 2003. Respondents were mailed up to three questionnaires, with the third mailing including \$20 to increase responses. Of the 2,000 potential respondents, 180 were no longer practicing or had incorrect addresses, leaving 1,820 eligible physicians and 1,144 final responses. The response rate for the survey was 63\%, according to the American Association for Public Opinion Research (AAPOR) response rate definition 4, and did not differ by age, region, or whether the physician was board certified or not, although men and foreign medical graduates were slightly less likely to respond (Curlin et al. 2006; American Association for Public Opinion Research 2011). 
Weights to account for this are included and used unless otherwise noted, and all presented analyses account for sample stratification.

To control for the religious concentration of the physician's county, I merged the 2000 Religious Congregation and Membership Study (RCMS) with the RSMPP. The RCMS was designed and completed by the Association of Statisticians of American Religious Bodies and Glenmary Research Center. The RCMS data was merged with the RSMPP, matched according to the physician's county. This allowed for the inclusion of a control reflecting the religious percent of that county. As there are known issues with the RCMS sampling, only the adjusted percentage was used (see Finke and Scheitle 2005).

\section{Analytic Method}

The lavaan package for $R$ was used throughout this analysis because while no latent variables were created and included, all of the following models are mediated path models (Yves 2012). All models were estimated using robust Huber-White standard errors and a Yuan-Bentler scaled test statistic because the dependent variables are not strictly normal and are also more categorical in nature than they are continuous in nature (Curran, West, and Finch 1996; White 1982; Yuan and Bentler 1998). Model fit was evaluated using the root mean square error of approximation (RMSEA) and the standardized root mean square residual (SRMR), both of which reflect better model fit as they approach zero, as well as the comparative fit index (CFI) and Tucker-Lewis Index (TLI), which both reflect better model fits as they approach 1.0. The religious/spiritual orientations, intrinsic religiosity, and religious coping are introduced in a stepwise manner.

\section{Variables}


There are five different dependent variables in this analysis, all of which are self-reported physician responses to religious or spiritual topics in the clinical setting. All of them begin with the question, "When religious/spiritual issues come up in discussions with patients, how often do you respond in the following ways?” Respondents are offered six response options ranging from “never” to “always” or “does not apply.” Each dependent variable is a different possible response to when patients bring up religion: "I listen carefully and empathetically," "I try to change the subject in a tactful way," "I encourage patients in their own religious/spiritual beliefs and practices,” “I respectfully share my own religious ideas and experiences,” and "I pray with the patient.”

Both direct and indirect relationships are of interest here. The exogenous variables for the direct paths are the religious/spiritual typology discussed above. The present study follows the same four-part religious/spiritual typology I used in an earlier study with RSMPP data (Franzen 2014). RSMPP respondents were asked two questions: one about how religious they are and a second about how spiritual they are. Each question had four response categories indicating that they are either very religious/spiritual, moderately religious/spiritual, slightly religious/spiritual, or not religious/spiritual at all. The two affirmative and the two negative responses were collapsed and a two-by-two typology was created, allowing for the system of dummies reflecting SBNR, RAS, RBNS, and NROS.

The indirect relationship of interest focuses on the relationship of the religious/spiritual orientations and other religion measures with the physician responses meditated by their views regarding whether religiosity or spirituality impacts patient health. The survey question asked respondents: “How much influence do you think religion/spirituality has on patients' health?” There were five response options, ranging from “very much” to “very little to none.” 
Additional religious measures were included in all models. I included the adjusted percent of people within the responding physician's county who are members at any given religious community or congregation (Finke and Scheitle 2005). I also included a dichotomous measure as to whether or not the physician had ever had a religious or spiritual experience while practicing medicine that changed his or her life. If there was such an experience, the physician may be more likely to see the relevance of religion for medicine. I also included how often the respondent reported attending religious services, measured with a nine-point scale ranging from "never" to "several time a week." A measure for religious affiliation was included as a system of dummy variables, with no religious affiliation, Jewish affiliation, Catholic affiliation, and an “other” affiliation category compared with a Protestant affiliation. One measure reflecting religious coping was used as an additional way to get a sense of religion's pervasive presence in the physician's life. The question states: “Think about how you try to understand and deal with major problems in your life. To what extent is the following involved in the way you cope: I look to God for strength, support, and guidance.” The response options ranged from "not at all” to "a great deal.” Finally, a validated measure for intrinsic religiosity was used (Hoge 1972). This was a combination of two measures: "I try hard to carry my religious beliefs over into all my other dealings in life" and "My whole approach to life is based on my religion.” Both had response options ranging from "strongly disagree" to "strongly agree."

Additional demographic or structural measures included whether or not physicians reported any barriers to including religious or spiritual content in their clinical interactions with patients. This was a system of dichotomous variables with "insufficient time" used as the comparison category as it is the most common barrier ( $47 \%$ of the sample reported this barrier) (see also Koenig 2014). The list of barriers to choose from included: "general discomfort with 
discussing religious matters," "insufficient knowledge/training,” "concern about offending patients," and "concern that my colleagues will disapprove." Whether or not physicians have received spiritual care training is an important factor in their ability or inclination to provide that care (Balboni et al. 2012). I have included a measure reflecting this, with a question asking, "Have you had any formal training regarding religion/spirituality in medicine?” with options of a "yes" or "no" response. Because others have shown that medical specializations differ in their religiosity (Curlin et al. 2005; Franzen 2014), I have included the respondent’s primary specialty. Family practice is used as the comparison category since family practice physicians tend to be more RAS or SBNR (Franzen 2014) and higher in intrinsic religiosity and religious coping (Curlin et al. 2005). Other controls include whether or not the physician works within an academic setting, a faith-based setting, whether or not they are a resident, whether they are board certified, and whether or not they practice primary care medicine. Finally, I included their age at the time of taking the survey, and whether or not they are white, male, and live in the south.

\section{RESULTS}

Table 1 shows the descriptive statistics and group mean differences for physician religious and spiritual orientations. Table 2 shows the Pearson's correlation coefficients between the key religion measures used here (religious/spiritual orientations, intrinsic religiosity, and religious coping) and the five physicians responses. We can see that respondents reporting RAS orientations also tend to have heightened reported levels of intrinsic religiosity as well as religious coping. Interestingly, both religious coping and intrinsic religiosity is negatively related to all of the other religious/spiritual orientations. RAS physicians always tend towards inclusion while SBNR physicians avoid playing an active role (avoiding sharing and praying). RBNS 
physicians are slightly unlikely to pray with patients, and NROS physicians tend towards avoiding all inclusion.

[Insert Table 1 about here]

[Insert Table 2 about here]

Figure 1 shows the general path model for all of the models shown in Tables 3 - 7. This paper is argues that the physician's own biographical past is important when considering what they see as relevant and irrelevant in clinical interactions. The path model allows me to measure which spiritual/religious orientation is most associated with having linked religious beliefs, health outcomes, and clinical interactions with patients. The model estimates both direct paths between religious/spiritual orientations and indirect paths between the orientations and interaction responses via the belief that religion matters for health outcomes. [insert Figure 1 about here]

\section{Direct Effects on the Mediation Measure}

I first describe the direct effects on whether or not the physician thinks religion/spirituality impacts patient health because they are, as they should be, basically the same for all five physician actions (Tables 3 - 7). In terms of demographic factors, male respondents, those who are still residents, and those who are board certified are less likely to think that religion/spirituality impacts health outcomes. Living in the south is marginally $(p<.1)$ tied to thinking religion/spirituality matters more often, but this effect is no longer present in Model 2 with the addition of intrinsic religiosity and religious coping. Physicians who practice a specialization within internal medicine are less likely to think that religion impacts the health of patients (Model 1). Once intrinsic religiosity and religious coping are added to the model, pediatricians are also marginally less likely to think religion impacts health (Model 2). 
Attendance at religious services is consistently and positively associated with thinking religion/spirituality impacts health. Having had a spiritual experience while working is positively associated with thinking religion/spirituality impacts health until religious coping is introduced into the model. Religious coping is positively associated with this belief, and it is a strong association (when looking at the standardized betas within each model), followed closely by the effect of intrinsic religiosity. While there is some slight variation across the models, Catholic respondents are less likely than Protestants to think that religion/spirituality impacts health. Finally, while the association between SBNR respondents and thinking religion/spirituality impacts health does not differ from RAS physicians in Model 2, RAS physicians are more likely to think this when compared with RBNS and NROS respondents.

[insert Table 3 about here]

\section{Direct Effects on Physician Actions}

Table 3 shows the results for the models predicting whether or not the physician was willing to share his or her own religious ideas and experiences with patients. Model 1 shows the results prior to the addition of intrinsic religiosity and religious coping, and all three of the religious/spiritual orientation direct effects are significantly less likely to share with patients as compared with RAS physicians. The variance for all three religious/spiritual orientations is confounded by the addition of intrinsic religiosity and religious coping in Model 2. Religious coping is positively associated with sharing with patients and is also the strongest effect in the model when looking at the standardized betas. The next strongest effect in the model is the mediation measure-whether or not the physician thinks religion/spirituality impacts patient 
health. The third strongest effect in the model is the positive association with intrinsic religiosity. Having had a spiritual experience while at work is positively associated with sharing, as is the barrier of being concerned about offending one's patients as compared to having insufficient time. Receiving training was positively associated with sharing as well. Almost all of the physician specializations are less prone to share beliefs with patients as compared with family practice physicians except for those claiming an internal medicine specialty and obstetrics. Those of a Jewish religious affiliation are less likely than Protestants to share their own beliefs, as are those who are older, work in an academic setting, and report that they lack training in dealing with religious/spiritual topics as compared to not having enough time. Overall, this model (Model 2) explains about 44\% of the variance in whether a physician shares their own beliefs and experiences with their patients.

[insert Table 4 about here]

Table 4 shows the models for whether or not the physician listens to the patient's religious/spiritual views. Overall, fewer of the variables were significant and this could be because physicians generally report being more willing to listen to patients (mean of 3.55 on a 4 point scale, with a standard deviation of only .66). Beginning with Model 1, none of the religious/spiritual orientations differ from RAS respondents. The mediation measure—-thinking religion impacts health outcomes_-is marginally significant $(p=0.6)$ and has a positive effect. Respondents who were trained in attending to patients' religious/spiritual concerns is positively associated with listening to them, as is working in an academic institution. Older respondents and those who are generally uncomfortable with these types of interactions (as compared with not having enough time) are less likely to listen to patients’ views. Possibly in line with their area of 
medicine, psychiatrists are more likely to listen to their patients' beliefs as compared with family medicine physicians. Overall this model (Model 2) explains about 12\% of the variation in whether or not the physician listens to the patients' views.

[insert Table 5 about here]

Table 5 shows the results for whether the physician tends to change the subject away from religious/spiritual topics. First, nearly the strongest effect in the model is that of the mediation measure, and it is an inverse relationship. Those who think that religion impacts health outcomes are less likely to change the subject when it comes up. Physicians who have religious/spiritual care training and those who are white, male, and board certified are all also less likely to change the subject. Physicians who report having no religious affiliation or an “other" affiliation (as compared to claiming a Protestant affiliation) and are either concerned they will offend their patient or are generally uncomfortable with these kinds of interactions (as compared with reporting a lack of time) are more likely to report that they tend to change the subject. Echoing Table 4, psychiatrists are less likely to change the subject away from religion as compared with family practice doctors, but "other" specializations and those practicing obstetrics are more likely. This model (Model 2) explains about $24 \%$ of the variation in who will tend to change the subject.

[insert Table 6 about here]

Only the NROS religious/spiritual orientation is marginally $(p<.1)$ associated with whether the physician encourages patients' religious/spiritual beliefs (Table 6), and they are less likely to do so as compared to RAS physicians. Physicians who report a higher level of religious 
coping are also marginally associated with encouraging their patients' beliefs more often. The strongest effect in the model is the positive association between thinking that religion impacts health outcomes and encouraging patients' religious beliefs. Finally, thinking that one’s colleagues may disapprove if they encouraged their patients' beliefs was negatively associated with doing so as compared to those who report that they have a lack of time. Pediatricians and “other” specializations are less likely than those practicing family practice to encourage patient beliefs. This model (Model 2) explains about 13\% of the variation in whether or not the physician tends to encourage the religious/spiritual beliefs of the patient.

[insert Table 7 about here]

Finally, Table 7 shows the result for the models predicting whether or not the physician tends to pray with their patients or not. Only one of the religious/spiritual orientations (SBNR) was marginally negatively associated with praying with patients as compared to RAS physicians, but this association does not remain once intrinsic religiosity is added to the model. Once religious coping is added to the model, intrinsic religiosity is also no longer significant. Religious coping is positively related to praying with patients and is the strongest effect in the model. Close in terms of effect strength is the positive association of both having received training in spiritual care and thinking that religion impacts patient health outcomes. Having had a spiritual experience at work is also positively associated with praying with patients. All but an "other" religious affiliation are significant and are less likely to pray with patients as compared to those claiming a Protestant affiliation. Looking at the barrier measures, such as having a general discomfort with these interactions, thinking that one’s colleagues will disapprove, or having some other barrier to providing spiritual care, we find that all are negatively associated with 
praying with patients as compared with reporting a lack of time. Again we see the propensity for passive engagement of psychiatrists because. while they are likely to listen (Table 4 and 5), they are unlikely to pray with patients as compared with family practice physicians, or pediatricians and internal medicine physicians. This model (Model 2) explains about 33\% of the variation in whether or not the physician tends to pray with their patients.

\section{Discussion and Conclusion}

I have argued here that how a physician interacts with patients and what they see as pertinent within clinical interactions will be guided by their own biography and cognitive schemas that connect religion/spirituality to medicine and thereby imply perceived relevance to greater or lesser degrees. While patients often want their beliefs to be a part of their care (Koenig 2014) and almost all physicians support the idea of patient-centered care (Kitson et al. 2013), cultural mismatches between physicians and patients can prevent physicians from perceiving all patients' contributions or cultural backgrounds as relevant or helpful in medical interactions (Dubbin et al. 2013). To rephrase this, a physician’s own beliefs, values, and experiences will drive what topics they think they need to discuss with their patients, potentially avoiding all topics outside of this horizon of relevance. How large or small this circle of relevance tends to be is of interest to medical care more generally, not specifically focusing on religious content. I have shown here that physicians’ religious/spiritual orientations, practices, and experiences are indeed related to how they respond to religious topics in clinical settings.

Specifically, those physicians who more strongly affirm that they think religion/spirituality influences patient health consistently tend toward including that content, whether that be sharing their own beliefs, praying with patients, or just not changing the subject when beliefs are brought up. Connecting the relevance of religion with patient health mediates 
the relationship between the actions and many of the other religious measures in the present models. As argued above, one of the defining characteristics of being spiritual (both for RAS physicians as well as SBNR physicians) is the importance of the beliefs in the person's life; it is not simply a habitual practice or contextually bounded dimension of that person's life (you do "religious" stuff at "religious” places, for example). The link between greater importance of religion/spirituality in one's life and a deeper schematic relevance that crosses domains (from one’s personal beliefs into their professional work, for example) (Johnson-Hanks et al. 2011) seems to be supported here as shown by the difference between SBNR physicians and RAS physicians no longer being present with the introduction of intrinsic religiosity. This is further supported by the significant and strong effect of religious coping. More than a century ago, Weber (1993) theorized that a key feature of religion is its ability to contextualize life experiences, especially struggles. This measure highlights, potentially more directly that others, some respondents' non-domain specific application of the relevance of God throughout all of their life, like a thin veneer applied to everything providing greater continuity to their disparate roles in life (Berger 1990).

One of the other more interesting relationships concerning whether or not the physician thinks religion matters for health outcomes is actually a lack of significance. Other work has shown the central importance of spiritual care training (Balboni et al. 2012), and here it is also shown to exert an important direct effect on physicians' actions. What is interesting, however, is that training is not associated with thinking that religion impacts patient health. This means that training leads to greater inclusion but apparently not because of a shift in physicians' thinking religion/spirituality impacts the health outcomes of their patients. This may be an important point for patient-centered care. Dubbin et al. (2013) show that interactions between physicians and 
patients flow primarily from physicians' perceptions of what should be going on in the clinic, and they voice skepticism regarding how flexible this is by means of education because one's habitus flows primarily from social structural location (see also Bourdieu 1977). However, our study demonstrates the importance of training for the inclusion of religion/spirituality in medical interactions, whether or not the physician thinks religion matters for health outcomes. Clearly this could be an indication that education can partially shift physicians' actions in clinical interactions toward greater patient-centered care, where inclusion of religiosity/spirituality is appropriate for that care.

Not all of the variance in the physicians' actions is mediated by the belief that religion impacts patients' health. Many of the final models (3 of 5) have additional variance explained by religious coping that is not mediated by thinking religion impacts health, with intrinsic religiosity also explaining some residual variance in one of the models. Two of the five outcomes show that Jewish respondents are less likely to engage with patients in this way as compared with Protestants, echoing previous findings (see Stern, Rasinski, and Curlin 2011). Academic settings appear to be more related to passive engagement (listening to patients talk) than active engagement (sharing one's own beliefs). Elder-Vass (Archer and Elder-Vass 2012; Elder-Vass 2008) posits that perceptions of appropriate action will be tied back to a network of others who hold similar perceptions. Hints of this appear in the relationship of the barriers in the present findings: a concern of disapproving colleagues is negatively related to two of the three active forms of religious/spiritual engagement (encouraging patients and praying with them) as compared to not having enough time.

A final point tying patient-centered care back into the presented results draws upon Weberian themes of authority developed by Starr. Starr (1982:14) observes that there are two 
different types of authority at work within the clinical setting: cultural authority and social authority. The first is the ability to construct reality through definitions of fact and value while the second is the direction and control of another's actions through commands. This is important for medical care and for concepts of patient-centered care specifically because although these two types of authority may correlate with one another, they are not coterminous. If a physician is unable to help the patient make sense of his or her experiences and frame it as a medical issue that can be ameliorated with the provided instructions (Halpern 2001; Jutel 2011; McLaughlin 2005), then there is little hope of that patient following those instructions. This matters for patient-centered care because if the patient is religious and makes sense of their world with those “tools” but their physician is not religious and doesn't at least acknowledge these tools as part of the illness experience, then the possibility of non-adherence increases. At the very least, it can be harder for the patient to merge their illness experience with the rest of their life (Marty 1982).

Several important limitations to this study should be noted. First, I have used crosssectional data and while it makes sense that one's orientation and religious practices influence inclusion and not the other way around, only the association can be established here. Additionally, the present findings rely on physicians' recall of clinical interactions and not the observation of those interactions or patients' report of those interactions. One other significant limitation that ought to be mentioned is the data used here is from 2003. While there is no better suited data available, much has changed in medical education and provision since 2003 that could alter the relationships presented here.

This study has brought up various potentially fruitful areas for further work on this topic. One is the differences between active and passive inclusion of religion in clinical interactions. When will a physician merely allow religion's presence and when will they engage with it? 
Second, structural factors in addition to cultural factors appear to be important and warrant further work. Third, it is not uncommon for patients to select which physician they see on an ongoing basis, even within a given practice, so a multilateral cultural selection process impacting clinical interactions would be highly valuable (Vaisey and Lizardo 2010). One potential dimension of this could be how mismatched religious individuals (e.g., a Hindu physician and a Christian patient) relate to one another in terms of religiosity/spirituality. Finally, more work needs to be done on how or why different religious/spiritual orientations are connected with perceptions of clinical relevance. While the RAS orientation was associated with inclusion, as mediated by a cognitive connection between religion and health outcomes, the pattern for other orientations was not as clear. SBNR physicians appear to avoid taking an active role and NROS physicians appear to always avoid inclusion. 


\section{References}

American Association for Public Opinion Research. 2011. Standard definitions: Final dispositions of case codes and outcome rate for surveys. Lenexa, KS: AAPOR.

Archer, Margaret S., and Dave Elder-Vass. 2012. Cultural system or norm circles? An exchange. European Journal of Social Theory 15(1):93-115.

Balboni, Michael J., Julia Bandini, Christine Mitchell, Zachary D. Epstein-Peterson, Ada Amobi, Jonathan Cahill, Andrea C. Enzinger, John Peteet, and Tracy Balboni. 2015. Religion, spirituality, and the hidden curriculum: Medical student and faculty reflections. Journal of Pain and Symptom Management, doi: 10.1016/j.jpainsymman.2015.04.020.

Balboni, Michael J., Adam Sullivan, Adaugo Amobi, Andrea C. Phelps, Daniel Gorman, Angelika Zollfrank, John R. Peteet, Holly G. Preigerson, Tyler J. VanderWeele, and Tracy A. Balboni. 2012. Why is spiritual care infrequent at the end of life? Spiritual care perceptions among patients, nurses, and physicians and the role of training. Journal of Clinical Oncology, doi: 10.1200/JCO.2012.44.6443.

Berger, Peter L. 1990. The sacred canopy: Elements of a sociological theory of religion. New York: Anchor Books.

Bernard, Lo, Timothy Quill, and James Tulsky. 1999. Discussing palliative care with patients. Annals of Internal Medicine 130(9):744.

Bourdieu, Pierre. 1977. Outline of a theory of practice. New York: Cambridge University Press.

Cadge, Wendy, Katherine Calle, and Jennifer Dillinger. 2011. What do chaplains contribute to large academic hospitals? The perspectives of pediatric physicians and chaplains. Journal of Religion and Health 50(2):300-312.

Cadge, Wendy, and Elaine Howard Ecklund. 2009. Prayers in the clinic: How pediatric physicians respond. Southern Medical Journal 102(12):1218-21.

Carel, Havi, and Jane Macnaughton. 2012. “How Do You Feel?”: Oscillating perspectives in the clinic. The Lancet 379(9834):2334-35.

Catlin, Elizabeth Ann, Wendy Cadge, Elaine Howard Ecklund, Elizabeth A. Gage, and Angelika Annette Zollfrank. 2008. The spiritual and religious identities, beliefs, and practices of academic pediatricians in the United States. Academic Medicine 83(12):1146-52.

Chatters, Linda M. 2000. Religion and health: Public health research and practice. Annual Review of Public Health 21:335-67.

Cohen, Adam B., and Peter C. Hill. 2007. Religion as culture: Religious individualism and collectivism among American Catholics, Jews, and Protestants. Journal of Personality 75(4):709-42. 
Curlin, Farr A., Marshall H. Chin, Sarah A. Sellergren, Chad J. Roach, and John D. Lantos. 2006. The Association of Physicians' religious characteristics with their attitudes and self-reported behaviors regarding religion and spirituality in the clinical encounter. Medical Care 44(5):446-53.

Curlin, Farr A., John D. Lantos, Chad J. Roach, Sarah A. Sellergren, and Marshall H. Chin. 2005. Religious characteristics of U.S. physicians: A national survey. Journal of General Internal Medicine 20(7):629-34.

Curlin, Farr A., Ryan E. Lawrence, Marshall H. Chin, and John D. Lantos. 2007. Religion, conscience, and controversial clinical practices. New England Journal of Medicine 356(18):1889-92.

Curran, Patrick J., Stephen G. West, and John F. Finch. 1996. The robustness of test statistics to nonnormality and specification error in confirmatory factor analysis. Psychological Methods 1(1):16-29.

Dougherty, Kevin D., and Sung Joon Jang. 2008. Spirituality: Religion and spirituality are not mutually exclusive. In What Americans really believe, edited by R. Stark, pp. 87-94. Waco, TX: Baylor University Press.

Dubbin, Leslie A., Jamie Suki Chang, and Janet K. Shim. 2013. Cultural health capital and the interactional dynamics of patient-centered care. Social Science \& Medicine 93:113-20.

Ehman, John W., Barbara B. Ott, Thomas H. Short, Ralph C. Ciampa, and John HansenFlaschen. 1999. Do patients want physicians to inquire about their spiritual or religious beliefs if they become gravely ill? Archives of Internal Medicine 159(15):1803-6.

Elder-Vass, Dave. 2008. Integrating institutional, relational and embodied structure: An emergentist perspective. The British Journal of Sociology 59(2):281-99.

Engel, George L. 1977. The need for a new medical model: A challenge for biomedicine. Science 196(4286):129-36.

Engel, George L. 1980. The clinical application of the biopsychosocial model. The American Journal of Psychiatry 137(5):535-44.

Epstein, Ronald M., Peter Franks, Kevin Fiscella, Cleveland G. Shields, Sean C. Meldrum, Richard L. Kravitz, and Paul R. Duberstein. 2005. Measuring patient-centered communication in patient-physician consultations: Theoretical and practical issues. Social Science \& Medicine 61(7):1516-28.

Finke, Roger, and Christopher P. Scheitle. 2005. Accounting for the uncounted: Computing correctives for the 2000 RCMS Data. Review of Religious Research 47(1):5-22.

Frank, Arthur W. 1991. At the will of the body: Reflections on illness. Boston, MA: Houghton Mifflin. 
Franzen, Aaron B. 2014. Physicians in the USA: Attendance, beliefs and patient interactions. Journal of Religion and Health, doi: 10.1007/s10943-014-9986-0.

Fuller, Robert C. 2001. Spiritual, but not teligious: Understanding unchurched America. Oxford: Oxford University Press.

Grossoehme, Daniel H., Judith R. Ragsdale, Christine L. McHenry, Celia Thurston, Thomas DeWitt, and Larry Vandecreek. 2007. Pediatrician characteristics associated with attention to spirituality and religion in clinical practice. Pediatrics 119(1):e117-23.

Halpern, Jodi. 2001. From detached concern to empathy: Humanizing medical practice. New York: Oxford University Press.

Hoge, Dean R. 1972. A validated intrinsic religious motivation scale. Journal for the Scientific Study of Religion 11(4):369-76.

Jang, Sung Joon, and Aaron B. Franzen. 2013. Is being “Spiritual” enough without being religious? A study of violent and property crimes among emerging adults. Criminology 51(3):595-627.

Johnson-Hanks, Jennifer, Christine A. Bachrach, S. Philip Morgan, and Hans-Peter Kohler. 2011. Understanding family change and variation: Toward a theory of conjunctural action. New York: Springer.

Jutel, Annemarie Goldstein. 2011. Putting a name to it: Diagnosis in contemporary society. Baltimore, MD: Johns Hopkins University Press.

King, Dana E., and Bruce Bushwick. 1994. Beliefs and attitudes of hospital inpatients about faith healing and prayer. The Journal of Family Practice 39(4):349-52.

Kitson, Alison, Amy Marshall, Katherine Bassett, and Kathryn Zeitz. 2013. What are the core elements of patient-centred care? A narrative review and synthesis of the literature from health policy, medicine and nursing. Journal of Advanced Nursing 69(1):4-15.

Koenig, Harold G. 2014. The spiritual care team: Enabling the practice of whole person medicine. Religions 5(4):1161-74.

Koenig, Harold G., Lucille B. Bearon, Margot Hover, and James L. Travis 3rd. 1991. Religious perspectives of doctors, nurses, patients, and families. Journal of Pastoral Care 45(3):254-67.

Light, Donald W. 2004. Ironies of success: A new history of the American health care "system.” Journal of Health and Social Behavior 45:1-24.

MacIntyre, Alasdair. 1977. Patients as agents. In Philosophical medical ethics: Its nature and significance, edited by Stuart F. Spicker, H. Tristram Englehardt, Jr., pp. 197-212.

Boston, MA: D. Reidel Pub. Co. 
MacLean, Charles D., Beth Susi, Nancy Phifer, Linda Shultz, Deborah Bynum, Mark Franco, Andria Klioze, Michael Monroe, Joanne Garrett, and Sam Cykert. 2003. Patient preference for physician discussion and practice of spirituality. Journal of General Internal Medicine 18(1):38-43.

Macnaughton, Jane. 2009. The dangerous practice of empathy. The Lancet 373(9679):1940-41.

Marty, Martin E. 1982. The intertwining of religion and health/medicine in culture: A view through the disciplines. In Health/medicine and the faith traditions: An inquiry into religion and medicine, edited by Martin E. Marty and Kenneth L. Vaux, pp. 27-50. Philadelphia: Fortress Press.

McLaughlin, J. 2005. Exploring diagnostic processes: Social science perspectives. Archives of Disease in Childhood 90(3):284-87.

McWhinney, Ian R. 1993. Why we need a new clinical method. Scandinavian Journal of Primary Health Care 11(1):3-7.

Mead, Nicola, and Peter Bower. 2000. Patient-centredness: A conceptual framework and review of the empirical literature. Social Science \& Medicine 51(7):1087-1110.

Pargament, Kenneth I. 1997. The psychology of religion and coping: Theory, research, practice. New York: Guilford Press.

Pepper, Miriam, Tim Jackson, and David Uzzell. 2010. A study of multidimensional religion constructs and values in the United Kingdom. Journal for the Scientific Study of Religion 49(1):127-46.

Phelps, Andrea C., Katherine E. Lauderdale, Sara Alcorn, Jennifer Dillinger, Michael T. Balboni, Michael Van Weert, Tyler S. Vander Weele, and Tracy A. Balboni. 2012. Addressing spirituality within the care of patients at the end of life: Perspectives of patients with advanced cancer, oncologists, and oncology nurses.” Journal of Clinical Oncology 30(20):2538-44.

Piedmont, Ralph L. 1999. Does spirituality represent the sixth factor of personality? Spiritual transcendence and the five-factor model. Journal of Personality 67(6):985-1013.

Porter, Roy. 1993. Religion and medicine. In The companion encyclopedia of the history of medicine 2, edited by William F. Bynum and Roy Porter, pp. 1449-68. NY: Routledge.

Roof, Wade Clark. 1993. A generation of seekers: The spiritual journeys of the baby boom generation. San Francisco, CA: HarperSanFrancisco.

Saucier, Gerard, and Katarzyna Skrzypinska. 2006. Spiritual but not religious? Evidence for two independent dispositions. Journal of Personality 74(5):1257-92. 
Schlehofer, Michele M., Allen M. Omoto, and Janice R. Adelman. 2008. How Do "Religion” and "Spirituality" differ? Lay definitions among older adults. Journal for the Scientific Study of Religion 47(3):411-25.

Schutz, Alfred. 1962a. Common-sense and scientific interpretation of human action. In Collected papers: The problem of social reality, vol. 1, edited by Maurice Nathanson, pp. 3-47. The Hague: Martinus Nijhoff.

Schutz, Alfred. 1962b. On multiple realities. In Collected Papers: The problem of social reality, vol. 1, edited by Maurice Nathanson, pp. 207-259. The Hague: Martinus Nijhoff.

Starr, Paul. 1982. The social transformation of American medicine. New York: Basic Books.

Stern, Robert M., Kenneth A. Rasinski, and Farr A. Curlin. 2011. Jewish physicians' beliefs and practices regarding religion/spirituality in the clinical encounter. Journal of Religion \& Health 50(4):806-17.

Stewart, Moira A. 1995. Effective physician-patient communication and health outcomes: A review. Canadian Medical Association Journal 152(9):1423-33.

Stewart, Moira A. 2001. Towards a global definition of patient centred care. British Medical Journal 322(7284):444-45.

Toombs, S. Kay. 1987. The meaning of illness: A phenomenological approach to the patientphysician relationship. Journal of Medicine and Philosophy 12(3):219-40.

Toombs, S. Kay. 1990. The temporality of illness: Four levels of experience. Theoretical Medicine 11(3):227-41.

Vaisey, Stephen, and Omar Lizardo. 2010. Can cultural worldviews influence network composition? Social Forces 88(4):1595-1618.

Weber, Max. 1993. The sociology of religion. Boston, MA: Beacon Press.

Wexler, Isaiah D., and Benjamin W. Corn. 2012. An existential approach to oncology: Meeting the needs of our patients. Current Opinion in Supportive \& Palliative Care 6(2):275-79.

White, Halbert. 1982. Maximum likelihood estimation of misspecified models. Econometrica 50(1):1-25.

Williams, Joshua A., David Meltzer, Vineet Arora, Grace Chung, and Farr A. Curlin. 2011. Attention to inpatients' religious and spiritual concerns: Predictors and association with patient satisfaction. Journal of General Internal Medicine 26(11):1265-71.

Winkelman, William D., Katherine Lauderdale, Michael Balboni, Andrea C. Phelps, John Peteet, Susan D. Block, Tracy A. Balboni, Lisa A. Kachnis, and Tyler J. VanderWeele. 2011. The relationship of spiritual concerns to the quality of life of advanced cancer patients: Preliminary findings. Journal of Palliative Medicine 14(9):1022-28. 
Wink, Paul, Lucia Ciciolla, Michele Dillon, and Allison Tracy. 2007. Religiousness, spiritual seeking, and personality: Findings from a longitudinal study. Journal of Personality 75(5):1051-70.

Wink, Paul, and Michele Dillon. 2003. Religiousness, spirituality, and psychosocial functioning in late adulthood: Findings from a longitudinal study. Psychology and Aging 18(4):91624.

World Health Organization. 2000. The world health report 2000 - health systems: Improving performance. Geneva: World Health Organization.

Wuthnow, Robert. 1998. After heaven: Spirituality in America since the 1950s. Berkeley, CA: University of California Press.

Yuan, Ke-Hai, and Peter M. Bentler. 1998. Normal theory based test statistics in structural equation modelling. British Journal of Mathematical and Statistical Psychology 51(2):289-309.

Yves, Rosseel. 2012. Lavaan: An R package for structural equation modeling. Journal of Statistical Software 48(2):1-36.

Zinnbauer, Brian J., Kenneth I. Pargament, Brenda Cole, Mark S. Rye, Eric M. Butter, Timothy G. Belavich, Kathleen M. Hipp, Allie B. Scott, and Jill L. Kadar. 1997. Religion and spirituality: Unfuzzying the fuzzy. Journal for the Scientific Study of Religion 36(4):54964.

Zwissler, Laurel. 2007. Spiritual, but religious: “Spirituality” among religiously motivated feminist activists. Culture and Religion 8(1):51. 
Table 1: Descriptive Statistics and Group Mean Differences

\begin{tabular}{|c|c|c|c|c|c|c|c|}
\hline & Range & Mean/\% & Std. Dev. & & Range & Mean/\% & Std. Dev. \\
\hline SBNR & 0,1 & 20 & & Attendance & $1-9$ & 4.97 & 2.43 \\
\hline RBNS & 0,1 & 4 & & Work Calling & $1-4$ & 3.01 & 0.82 \\
\hline NROS & 0,1 & 22 & & Academic & 0,1 & 32 & \\
\hline RAS & 0,1 & 52 & & Faith Based Practice & 0,1 & 12 & \\
\hline Religion Impacts Health & $1-5$ & 3.68 & 0.99 & Resident & 0,1 & 1 & \\
\hline Religious Affiliation & & & & Board Certification & 0,1 & 87 & \\
\hline Protestant & 0,1 & 33.33 & & Spiritual Care Training & 0,1 & 24 & \\
\hline Jewish & 0,1 & 16.09 & & Age & $28-66$ & 50.01 & 8.34 \\
\hline Catholic & 0,1 & 21.69 & & Physician Specialty & & & \\
\hline Other & 0,1 & 18.76 & & Other Specialty & 0,1 & 17 & \\
\hline None & 0,1 & 10.13 & & Internal Medicine & 0,1 & 11 & \\
\hline Intrinsic Religiosity & $2-8$ & 4.87 & 1.76 & Internal Specialty & 0,1 & 20 & \\
\hline Religious Coping & $1-4$ & 2.54 & 1.13 & OB & 0,1 & 7 & \\
\hline Religious Area & $0-110$ & 63.10 & 16.96 & Pediatrics & 0,1 & 8 & \\
\hline Barriers & & & & Psychiatry & 0,1 & 9 & \\
\hline Discomfort & 0,1 & 21 & & Surgery & 0,1 & 9 & \\
\hline Knowledge/Training & 0,1 & 25 & & Pediatric Specialty & 0,1 & 5 & \\
\hline Time & 0,1 & 47 & & Dependent Variables & & & \\
\hline Concern for Offending & 0,1 & 39 & & Share beliefs & $0-4$ & 1.28 & 1.04 \\
\hline Concern for Disapproval & 0,1 & 4 & & Listen & $0-4$ & 3.55 & 0.66 \\
\hline Other & 0,1 & 2 & & Change subject & $0-4$ & 0.88 & 0.89 \\
\hline White & 0,1 & 79 & & Encourage patient beliefs & $0-4$ & 3.03 & 0.96 \\
\hline Male & 0,1 & 74 & & Pray with patient & $0-4$ & 0.77 & 0.86 \\
\hline Spiritual Experience & 0,1 & 11 & & & & & \\
\hline
\end{tabular}




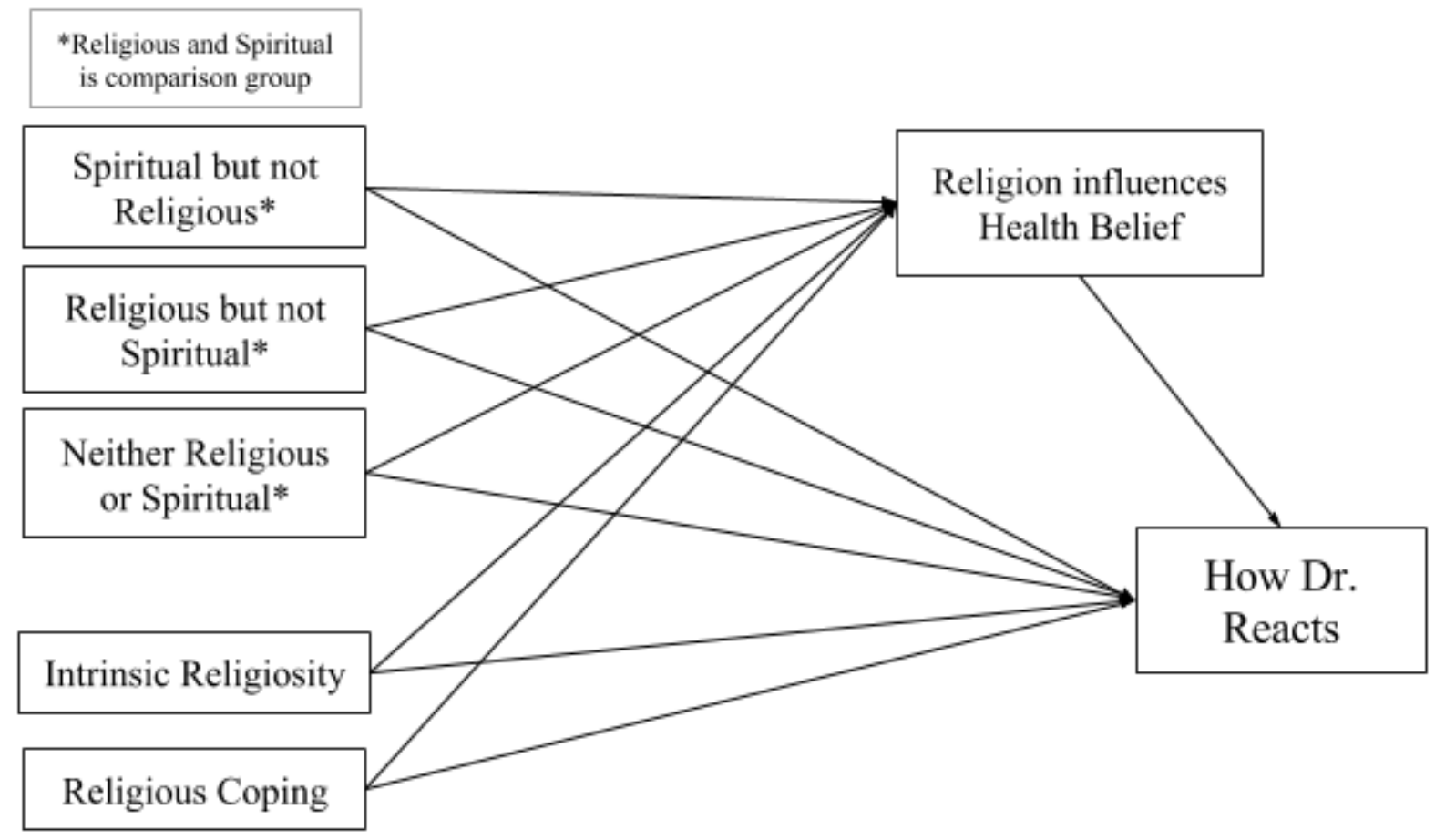

Figure 1: Path Model for How Physician Handles Religion in the Clinical Context 
Table 2: Pearson's Correlations Between Key Religion Measures and Physician-Patient Actions

\begin{tabular}{|c|c|c|c|c|c|c|c|c|c|c|}
\hline & RAS & SBNR & RBNS & NROS & Int. Religion & Rel. Cope & Share & Listen & Change & Encourage \\
\hline SBNR & $-0.526^{*}$ & & & & & & & & & \\
\hline RBNS & $-0.214^{*}$ & $-0.103^{*}$ & & & & & & & & \\
\hline NROS & $-0.549 *$ & $-0.265^{*}$ & $-0.108^{*}$ & & & & & & & \\
\hline Int. Religion & $0.579 *$ & $-0.232 *$ & -0.003 & $-0.483^{*}$ & & & & & & \\
\hline Rel. Cope & $0.635^{*}$ & $-0.278^{*}$ & -0.004 & $-0.496^{*}$ & $0.695 *$ & & & & & \\
\hline Share & $0.452 *$ & $-0.153^{*}$ & -0.051 & $-0.376^{*}$ & $0.505^{*}$ & $0.562 *$ & & & & \\
\hline Listen & $0.142 *$ & 0.026 & -0.005 & $-0.185 *$ & $0.175^{*}$ & $0.172 *$ & $0.207^{*}$ & & & \\
\hline Change & $-0.226^{*}$ & 0.043 & 0.049 & $0.209 *$ & $-0.251^{*}$ & $-0.249 *$ & $-0.259 *$ & $-0.340 *$ & & \\
\hline Encourage & $0.193^{*}$ & 0.015 & -0.006 & $-0.223^{*}$ & $0.182 *$ & $0.216^{*}$ & $0.283^{*}$ & $0.384 *$ & $-0.282 *$ & \\
\hline Pray & $0.347 *$ & $-0.124^{*}$ & $-0.060 *$ & $-0.280 *$ & $0.378^{*}$ & $0.450 *$ & $0.543 *$ & $0.192 *$ & $-0.233 *$ & $0.223^{*}$ \\
\hline
\end{tabular}

Source: Religion and Spirituality in Medicine: Physicians' Perspectives; $n=1142$; $<<.05$ *. 
Table 3: How often Physician Speaks with Patients about their own Religious or Spiritual Beliefs

\begin{tabular}{|c|c|c|c|c|c|c|c|c|c|c|c|c|}
\hline & \multicolumn{6}{|c|}{ Model 1} & \multicolumn{6}{|c|}{ Model 2} \\
\hline & \multicolumn{3}{|c|}{$\begin{array}{c}\text { Direct Effects on } \\
\text { Relig. Impacts Health }\end{array}$} & \multicolumn{3}{|c|}{$\begin{array}{c}\text { Direct Effects on } \\
\text { Share Beliefs }\end{array}$} & \multicolumn{3}{|c|}{$\begin{array}{c}\text { Direct Effects on } \\
\text { Relig. Impacts Health }\end{array}$} & \multicolumn{3}{|c|}{$\begin{array}{c}\text { Direct Effects on } \\
\text { Share Beliefs } \\
\end{array}$} \\
\hline & $b$ & $\beta$ & $\mathrm{SE}$ & $b$ & $\beta$ & $\mathrm{SE}$ & $b$ & $\beta$ & $\mathrm{SE}$ & $b$ & $\beta$ & SE \\
\hline \multicolumn{13}{|l|}{$\mathrm{R} / \mathrm{S}$ Orientations } \\
\hline $\mathrm{SBNR}^{\mathrm{a}}$ & $-0.18 *$ & -0.07 & 0.08 & $-0.28 * *$ & -0.11 & 0.08 & 0.05 & 0.02 & 0.08 & -0.11 & -0.04 & 0.08 \\
\hline $\mathrm{RBNS}^{\mathrm{a}}$ & $-0.57 * *$ & -0.11 & 0.12 & $-0.23+$ & -0.04 & 0.13 & $-0.44 * *$ & -0.09 & 0.12 & -0.17 & -0.03 & 0.13 \\
\hline $\mathrm{NROS}^{\mathrm{a}}$ & $-0.81 * *$ & -0.34 & 0.09 & $-0.30 * *$ & -0.12 & 0.09 & $-0.49 * *$ & -0.21 & 0.09 & -0.09 & -0.04 & 0.09 \\
\hline Religion Impacts Health & - & - & - & $0.24 * *$ & 0.23 & 0.03 & - & - & - & $0.17 * *$ & 0.16 & 0.03 \\
\hline \multicolumn{13}{|l|}{ Religious Affiliation } \\
\hline None & $-0.22 *$ & -0.07 & 0.11 & $-0.24 * *$ & -0.07 & 0.09 & -0.05 & -0.01 & 0.10 & -0.12 & -0.03 & 0.10 \\
\hline Jewish & $-0.29 * *$ & -0.11 & 0.08 & $-0.26 * *$ & -0.09 & 0.08 & -0.13 & -0.05 & 0.08 & $-0.15+$ & -0.05 & 0.08 \\
\hline Catholic & $-0.23 * *$ & -0.09 & 0.07 & -0.12 & -0.05 & 0.07 & $-0.15 *$ & -0.07 & 0.06 & -0.07 & -0.03 & 0.07 \\
\hline Other & -0.05 & -0.02 & 0.08 & -0.02 & -0.01 & 0.08 & -0.03 & -0.01 & 0.08 & 0.00 & 0.00 & 0.07 \\
\hline Spiritual Experience & $0.32 * *$ & 0.10 & 0.07 & $0.25 * *$ & 0.08 & 0.09 & $0.25 * *$ & 0.08 & 0.06 & $0.22 * *$ & 0.07 & 0.08 \\
\hline Attendance & $0.07 * *$ & 0.16 & 0.02 & $0.07 * *$ & 0.16 & 0.02 & 0.01 & 0.02 & 0.02 & 0.02 & 0.05 & 0.02 \\
\hline Internal Religiosity & - & - & - & - & - & - & $0.08 * *$ & 0.14 & 0.02 & $0.07 * *$ & 0.11 & 0.02 \\
\hline Religious Coping & - & - & - & - & - & - & $0.25 * *$ & 0.29 & 0.04 & $0.21 * *$ & 0.23 & 0.04 \\
\hline Training & 0.08 & 0.04 & 0.06 & $0.22 * *$ & 0.09 & 0.06 & 0.04 & 0.02 & 0.06 & $0.19 * *$ & 0.08 & 0.06 \\
\hline Religious Area & - & - & - & 0.00 & 0.00 & 0.00 & - & - & - & 0.00 & 0.00 & 0.00 \\
\hline White & -0.03 & -0.01 & 0.07 & $-0.18 *$ & -0.07 & 0.07 & 0.04 & 0.02 & 0.07 & $-0.13+$ & -0.05 & 0.07 \\
\hline Male & $-0.16 * *$ & -0.07 & 0.06 & $0.14 *$ & 0.06 & 0.06 & $-0.09+$ & -0.04 & 0.06 & $0.19 * *$ & 0.08 & 0.06 \\
\hline Academic Setting & -0.04 & -0.02 & 0.05 & $-0.17 * *$ & -0.08 & 0.05 & -0.01 & -0.01 & 0.05 & $-0.16 * *$ & -0.07 & 0.05 \\
\hline Faith Based Practice & 0.04 & 0.01 & 0.07 & 0.01 & 0.00 & 0.08 & 0.02 & 0.01 & 0.07 & 0.00 & 0.00 & 0.07 \\
\hline Resident & $-0.77 * *$ & -0.08 & 0.22 & 0.19 & 0.02 & 0.30 & $-0.65 * *$ & -0.07 & 0.24 & 0.23 & 0.02 & 0.28 \\
\hline Board Certification & $-0.26 * *$ & -0.09 & 0.08 & -0.09 & -0.03 & 0.08 & $-0.16 *$ & -0.06 & 0.07 & -0.04 & -0.01 & 0.08 \\
\hline Age & 0.00 & -0.03 & 0.00 & $-0.01 *$ & -0.06 & 0.00 & 0.00 & -0.02 & 0.00 & $-0.01 *$ & -0.05 & 0.00 \\
\hline \multicolumn{13}{|l|}{ Physician Specialty ${ }^{\mathrm{b}}$} \\
\hline Other & -0.06 & -0.02 & 0.08 & $-0.26 * *$ & -0.09 & 0.09 & -0.04 & -0.02 & 0.08 & $-0.25 * *$ & -0.09 & 0.09 \\
\hline Internal Medicine & 0.01 & 0.00 & 0.10 & $-0.26 *$ & -0.08 & 0.10 & 0.07 & 0.02 & 0.09 & $-0.21 *$ & -0.06 & 0.10 \\
\hline Internal Specialization & $-0.21 *$ & -0.08 & 0.08 & -0.11 & -0.04 & 0.09 & $-0.17 *$ & -0.07 & 0.08 & -0.10 & -0.04 & 0.09 \\
\hline OB & -0.06 & -0.02 & 0.11 & -0.15 & -0.04 & 0.12 & -0.04 & -0.01 & 0.11 & -0.14 & -0.04 & 0.11 \\
\hline Pediatrics & -0.18 & -0.05 & 0.11 & $-0.28 * *$ & -0.07 & 0.11 & $-0.19+$ & -0.05 & 0.11 & $-0.31 * *$ & -0.08 & 0.11 \\
\hline Psychiatry & 0.01 & 0.00 & 0.11 & $-0.42 * *$ & -0.11 & 0.10 & 0.04 & 0.01 & 0.10 & $-0.39 * *$ & -0.11 & 0.10 \\
\hline Surgery & -0.07 & -0.02 & 0.12 & -0.15 & -0.04 & 0.11 & -0.08 & -0.02 & 0.11 & $-0.18+$ & -0.05 & 0.11 \\
\hline Pediatrics Specialty & -0.18 & -0.04 & 0.12 & $-0.24+$ & -0.05 & 0.13 & -0.12 & -0.03 & 0.11 & $-0.22+$ & -0.05 & 0.12 \\
\hline South & $0.09+$ & 0.04 & 0.05 & -0.04 & -0.02 & 0.06 & 0.07 & 0.04 & 0.05 & -0.05 & -0.02 & 0.05 \\
\hline \multicolumn{13}{|l|}{ Barriers to Inclusion $^{c}$} \\
\hline General Discomfort & - & - & - & $-0.29 * *$ & -0.11 & 0.06 & - & - & - & $-0.25 * *$ & -0.10 & 0.06 \\
\hline Lack of knowledge/Training & - & - & - & $-0.17 * *$ & -0.07 & 0.06 & - & - & - & $-0.15 *$ & -0.06 & 0.06 \\
\hline Concerned about Offending & - & - & - & $0.12 *$ & 0.06 & 0.05 & - & - & - & $0.10 *$ & 0.05 & 0.05 \\
\hline Colleagues may Disapprove & - & - & - & 0.18 & 0.03 & 0.14 & - & - & - & 0.12 & 0.02 & 0.14 \\
\hline Other & - & - & - & -0.16 & -0.02 & 0.24 & - & - & - & -0.12 & -0.01 & 0.26 \\
\hline \multicolumn{13}{|l|}{$R^{2}$} \\
\hline Religion Impacts Health & \multicolumn{6}{|c|}{0.326} & \multicolumn{6}{|c|}{0.383} \\
\hline Share Beliefs & \multicolumn{6}{|c|}{0.4} & \multicolumn{6}{|c|}{0.436} \\
\hline CFI & \multicolumn{6}{|c|}{0.984} & \multicolumn{6}{|c|}{0.992} \\
\hline TLI & \multicolumn{6}{|c|}{0.825} & & & & & & \\
\hline RMSEA (95\% CIs) & & & $47(0$. & 7 - 0.069) & & & & 0.0 & $35(0.1$ & $1-0.058)$ & & \\
\hline SRMR & & & & & & & & & & & & \\
\hline
\end{tabular}

Source : Religion and Spirituality in Medicine: Physicians' Perspectives; $n=1142 ; \mathrm{p}<.01 * * ; \mathrm{p}<.05 * ; \mathrm{p}<.1+\left(\right.$ two-tailed tests); ${ }^{\text {a }}$ RAS is the comparison category; ${ }^{\mathrm{b}}$ Family practice is the comparison category; ${ }^{\mathrm{c}}$ Lack of time is comparison category. 
Table 4: How often Physicians Listen to Patients' Religious or Spiritual Views

\begin{tabular}{|c|c|c|c|c|c|c|c|c|c|c|c|c|}
\hline & \multicolumn{6}{|c|}{ Model 1} & \multicolumn{6}{|c|}{ Model 2} \\
\hline & \multicolumn{3}{|c|}{$\begin{array}{c}\text { Direct Effects on } \\
\text { Relig. Impacts Health } \\
\end{array}$} & \multicolumn{3}{|c|}{$\begin{array}{l}\text { Direct Effects on } \\
\text { Listen }\end{array}$} & \multicolumn{3}{|c|}{$\begin{array}{c}\text { Direct Effects on } \\
\text { Relig. Impacts Health } \\
\end{array}$} & \multicolumn{3}{|c|}{$\begin{array}{c}\text { Direct Effects on } \\
\text { Listen } \\
\end{array}$} \\
\hline & $b$ & $\beta$ & $\mathrm{SE}$ & $b$ & $\beta$ & $\mathrm{SE}$ & $b$ & $\beta$ & $\mathrm{SE}$ & $b$ & $\beta$ & $\mathrm{SE}$ \\
\hline \multicolumn{13}{|l|}{$\mathrm{R} / \mathrm{S}$ Orientations } \\
\hline $\mathrm{SBNR}^{\mathrm{a}}$ & $-0.18 *$ & -0.07 & 0.08 & 0.01 & 0.01 & 0.06 & 0.05 & 0.02 & 0.08 & 0.04 & 0.02 & 0.06 \\
\hline $\mathrm{RBNS}^{\mathrm{a}}$ & $-0.57 * *$ & -0.11 & 0.12 & 0.04 & 0.01 & 0.12 & $-0.44 * *$ & -0.09 & 0.12 & 0.05 & 0.01 & 0.12 \\
\hline NROS $^{\mathrm{a}}$ & $-0.82 * *$ & -0.34 & 0.09 & -0.08 & -0.05 & 0.07 & $-0.49 * *$ & -0.21 & 0.09 & -0.05 & -0.03 & 0.08 \\
\hline Religion Impacts Health & - & - & - & $0.06 *$ & 0.09 & 0.03 & - & - & - & $0.05+$ & 0.08 & 0.03 \\
\hline \multicolumn{13}{|l|}{ Religious Affiliation } \\
\hline None & $-0.22 *$ & -0.07 & 0.11 & -0.13 & -0.06 & 0.09 & -0.04 & -0.01 & 0.10 & -0.11 & -0.05 & 0.09 \\
\hline Jewish & $-0.29 * *$ & -0.11 & 0.08 & -0.11 & -0.06 & 0.07 & -0.12 & -0.05 & 0.08 & -0.09 & -0.05 & 0.07 \\
\hline Catholic & $-0.22 * *$ & -0.09 & 0.07 & -0.07 & -0.04 & 0.05 & $-0.15 *$ & -0.07 & 0.06 & -0.06 & -0.04 & 0.05 \\
\hline Other & -0.05 & -0.02 & 0.08 & -0.10 & -0.06 & 0.06 & -0.03 & -0.01 & 0.08 & -0.09 & -0.05 & 0.06 \\
\hline Spiritual Experience & $0.32 * *$ & 0.10 & 0.07 & 0.05 & 0.02 & 0.05 & $0.25 * *$ & 0.08 & 0.06 & 0.04 & 0.02 & 0.05 \\
\hline Attendance & $0.07 * *$ & 0.16 & 0.02 & 0.00 & 0.00 & 0.01 & 0.01 & 0.02 & 0.02 & -0.01 & -0.03 & 0.01 \\
\hline Internal Religiosity & - & - & - & - & - & - & $0.08 * *$ & 0.14 & 0.02 & 0.01 & 0.03 & 0.02 \\
\hline Religious Coping & - & - & - & - & - & - & $0.25 * *$ & 0.29 & 0.04 & 0.04 & 0.06 & 0.03 \\
\hline Training & 0.08 & 0.04 & 0.06 & $0.10 *$ & 0.06 & 0.05 & 0.04 & 0.02 & 0.06 & $0.09 *$ & 0.06 & 0.04 \\
\hline Religious Area & - & - & - & 0.00 & -0.02 & 0.00 & - & - & - & 0.00 & -0.02 & 0.00 \\
\hline White & -0.03 & -0.01 & 0.07 & 0.09 & 0.06 & 0.06 & 0.03 & 0.01 & 0.07 & $0.10+$ & 0.06 & 0.06 \\
\hline Male & $-0.16 * *$ & -0.07 & 0.06 & -0.02 & -0.02 & 0.04 & $-0.09+$ & -0.04 & 0.06 & -0.02 & -0.01 & 0.04 \\
\hline Academic Setting & -0.02 & -0.01 & 0.05 & $0.11 *$ & 0.08 & 0.04 & -0.01 & 0.00 & 0.05 & $0.11 * *$ & 0.08 & 0.04 \\
\hline Faith Based Practice & 0.04 & 0.01 & 0.07 & 0.00 & 0.00 & 0.06 & 0.02 & 0.01 & 0.07 & 0.00 & 0.00 & 0.06 \\
\hline Resident & $-0.75 * *$ & -0.08 & 0.23 & -0.03 & -0.01 & 0.18 & $-0.65 * *$ & -0.07 & 0.24 & -0.02 & 0.00 & 0.18 \\
\hline Board Certification & $-0.23 * *$ & -0.08 & 0.08 & 0.04 & 0.02 & 0.06 & $-0.16 *$ & -0.06 & 0.07 & 0.05 & 0.03 & 0.06 \\
\hline Age & 0.00 & -0.03 & 0.00 & $-0.01 * *$ & -0.10 & 0.00 & 0.00 & -0.02 & 0.00 & $-0.01 * *$ & -0.10 & 0.00 \\
\hline \multicolumn{13}{|l|}{ Physician Specialty } \\
\hline Other & -0.06 & -0.02 & 0.08 & $-0.12+$ & -0.07 & 0.07 & -0.04 & -0.02 & 0.08 & $-0.12+$ & -0.07 & 0.07 \\
\hline Internal Medicine & 0.01 & 0.00 & 0.10 & 0.01 & 0.00 & 0.07 & 0.07 & 0.02 & 0.09 & 0.02 & 0.01 & 0.07 \\
\hline Internal Specialization & $-0.20 *$ & -0.08 & 0.08 & -0.01 & -0.01 & 0.06 & $-0.17 *$ & -0.07 & 0.08 & -0.01 & -0.01 & 0.07 \\
\hline $\mathrm{OB}$ & -0.06 & -0.02 & 0.11 & 0.04 & 0.02 & 0.08 & -0.04 & -0.01 & 0.11 & 0.04 & 0.02 & 0.08 \\
\hline Pediatrics & -0.17 & -0.05 & 0.11 & 0.01 & 0.01 & 0.08 & $-0.19+$ & -0.05 & 0.11 & 0.01 & 0.00 & 0.08 \\
\hline Psychiatry & 0.02 & 0.01 & 0.11 & $0.16 *$ & 0.07 & 0.07 & 0.04 & 0.01 & 0.10 & $0.16 *$ & 0.07 & 0.07 \\
\hline Surgery & -0.07 & -0.02 & 0.12 & -0.08 & -0.03 & 0.09 & -0.08 & -0.02 & 0.11 & -0.08 & -0.04 & 0.09 \\
\hline Pediatrics Specialty & -0.17 & -0.04 & 0.12 & 0.02 & 0.01 & 0.08 & -0.12 & -0.03 & 0.11 & 0.02 & 0.01 & 0.08 \\
\hline South & $0.09+$ & 0.05 & 0.05 & 0.01 & 0.01 & 0.04 & 0.08 & 0.04 & 0.05 & 0.01 & 0.01 & 0.04 \\
\hline \multicolumn{13}{|l|}{ Barriers to Inclusion $^{c}$} \\
\hline General Discomfort & - & - & - & $-0.26 * *$ & -0.16 & 0.06 & - & - & - & $-0.25 * *$ & -0.16 & 0.06 \\
\hline Lack of knowledge/Training & - & - & - & -0.03 & -0.02 & 0.05 & - & - & - & -0.03 & -0.02 & 0.05 \\
\hline Concerned about Offending & - & - & - & 0.05 & 0.04 & 0.04 & - & - & - & 0.05 & 0.03 & 0.04 \\
\hline Colleagues may Disapprove & - & - & - & -0.09 & -0.03 & 0.11 & - & - & - & -0.10 & -0.03 & 0.11 \\
\hline Other & - & - & - & 0.08 & 0.02 & 0.22 & - & - & - & 0.09 & 0.02 & 0.22 \\
\hline \multicolumn{13}{|l|}{$R^{2}$} \\
\hline Religion Impacts Health & \multicolumn{6}{|c|}{0.326} & \multicolumn{6}{|c|}{0.382} \\
\hline Listen to Patients & \multicolumn{6}{|c|}{0.118} & \multicolumn{6}{|c|}{0.121} \\
\hline CFI & \multicolumn{6}{|c|}{0.972} & \multicolumn{6}{|c|}{0.987} \\
\hline TLI & \multicolumn{6}{|c|}{0.698} & & & 0 & & & \\
\hline RMSEA (95\% CIs) & & & $46(0.1$ & $6-0.068)$ & & & & & $034(0$. & $1-0.058)$ & & \\
\hline SRMR & & & & & & & & & & 03 & & \\
\hline
\end{tabular}

Source : Religion and Spirituality in Medicine: Physicians' Perspectives; $n=1142 ; \mathrm{p}<.01 * * ; \mathrm{p}<.05 * ; \mathrm{p}<.1+$ (two-tailed tests); ${ }^{*}$ RAS is the comparison category; ${ }^{\mathrm{b}}$ Family practice is the comparison category; ${ }^{\mathrm{c}}$ Lack of time is comparison category. 
Table 5: How often Physicians Change Subject or Avoid Religious or Spiritual Topics

\begin{tabular}{|c|c|c|c|c|c|c|c|c|c|c|c|c|}
\hline & \multicolumn{6}{|c|}{ Model 1} & \multicolumn{6}{|c|}{ Model 2} \\
\hline & \multicolumn{3}{|c|}{$\begin{array}{c}\text { Direct Effects on } \\
\text { Relig. Impacts Health }\end{array}$} & \multicolumn{3}{|c|}{$\begin{array}{l}\text { Direct Effects on } \\
\text { Change Subject }\end{array}$} & \multicolumn{3}{|c|}{$\begin{array}{c}\text { Direct Effects on } \\
\text { Relig. Impacts Health }\end{array}$} & \multicolumn{3}{|c|}{$\begin{array}{l}\text { Direct Effects on } \\
\text { Change Subject }\end{array}$} \\
\hline & $b$ & $\beta$ & $\mathrm{SE}$ & $b$ & $\beta$ & $\mathrm{SE}$ & $b$ & $\beta$ & $\mathrm{SE}$ & $b$ & $\beta$ & $\mathrm{SE}$ \\
\hline \multicolumn{13}{|l|}{ R/S Orientations } \\
\hline $\mathrm{SBNR}^{\mathrm{a}}$ & $-0.18 *$ & -0.07 & 0.08 & 0.11 & 0.05 & 0.08 & 0.05 & 0.02 & 0.08 & 0.06 & 0.03 & 0.08 \\
\hline $\mathrm{RBNS}^{\mathrm{a}}$ & $-0.57 * *$ & -0.11 & 0.12 & 0.12 & 0.03 & 0.13 & $-0.44 * *$ & -0.09 & 0.12 & 0.11 & 0.02 & 0.12 \\
\hline NROS $^{\mathrm{a}}$ & $-0.82 * *$ & -0.34 & 0.09 & 0.06 & 0.03 & 0.09 & $-0.49 * *$ & -0.21 & 0.09 & -0.01 & 0.00 & 0.09 \\
\hline Religion Impacts Health & - & - & - & $-0.20 * *$ & -0.22 & 0.04 & - & - & - & $-0.18 * *$ & -0.20 & 0.04 \\
\hline \multicolumn{13}{|l|}{ Religious Affiliation } \\
\hline None & $-0.22 *$ & -0.07 & 0.11 & $0.29 * *$ & 0.10 & 0.11 & -0.04 & -0.01 & 0.10 & $0.26 *$ & 0.09 & 0.11 \\
\hline Jewish & $-0.29 * *$ & -0.11 & 0.08 & $0.14+$ & 0.06 & 0.09 & -0.12 & -0.05 & 0.08 & 0.11 & 0.05 & 0.09 \\
\hline Catholic & $-0.22 * *$ & -0.09 & 0.07 & -0.01 & 0.00 & 0.06 & $-0.15 *$ & -0.06 & 0.06 & -0.02 & -0.01 & 0.06 \\
\hline Other & -0.05 & -0.02 & 0.08 & $0.12+$ & 0.05 & 0.07 & -0.03 & -0.01 & 0.08 & 0.12 & 0.05 & 0.07 \\
\hline Spiritual Experience & $0.32 * *$ & 0.10 & 0.07 & 0.09 & 0.03 & 0.07 & $0.25 * *$ & 0.08 & 0.06 & 0.11 & 0.04 & 0.07 \\
\hline Attendance & $0.07 * *$ & 0.16 & 0.02 & 0.00 & 0.00 & 0.01 & 0.01 & 0.02 & 0.02 & 0.01 & 0.04 & 0.02 \\
\hline Internal Religiosity & - & - & - & - & - & - & $0.08 * *$ & 0.14 & 0.02 & -0.03 & -0.06 & 0.02 \\
\hline Religious Coping & - & - & - & - & - & - & $0.25 * *$ & 0.29 & 0.04 & -0.05 & -0.06 & 0.04 \\
\hline Training & 0.08 & 0.04 & 0.06 & $-0.12 *$ & -0.06 & 0.06 & 0.04 & 0.02 & 0.06 & $-0.11+$ & -0.05 & 0.06 \\
\hline Religious Area & - & - & - & $0.00 *$ & 0.06 & 0.00 & - & - & - & $0.00 *$ & 0.06 & 0.00 \\
\hline White & -0.03 & -0.01 & 0.07 & $-0.13+$ & -0.06 & 0.07 & 0.04 & 0.01 & 0.07 & $-0.13+$ & -0.06 & 0.07 \\
\hline Male & $-0.16 * *$ & -0.07 & 0.06 & $-0.12 *$ & -0.06 & 0.06 & $-0.09+$ & -0.04 & 0.06 & $-0.14 *$ & -0.07 & 0.06 \\
\hline Academic Setting & -0.02 & -0.01 & 0.05 & -0.01 & -0.01 & 0.06 & -0.01 & -0.01 & 0.05 & -0.01 & -0.01 & 0.06 \\
\hline Faith Based Practice & 0.04 & 0.01 & 0.07 & 0.02 & 0.01 & 0.08 & 0.02 & 0.01 & 0.07 & 0.03 & 0.01 & 0.08 \\
\hline Resident & $-0.74 * *$ & -0.08 & 0.22 & -0.18 & -0.02 & 0.24 & $-0.65 * *$ & -0.07 & 0.24 & -0.20 & -0.03 & 0.25 \\
\hline Board Certification & $-0.23 * *$ & -0.08 & 0.08 & -0.13 & -0.05 & 0.08 & $-0.16 *$ & -0.06 & 0.07 & $-0.14+$ & -0.06 & 0.08 \\
\hline Age & 0.00 & -0.03 & 0.00 & 0.00 & 0.01 & 0.00 & 0.00 & -0.02 & 0.00 & 0.00 & 0.01 & 0.00 \\
\hline \multicolumn{13}{|l|}{ Physician Specialty ${ }^{\mathrm{b}}$} \\
\hline Other & -0.06 & -0.02 & 0.08 & $0.34 * *$ & 0.15 & 0.09 & -0.04 & -0.02 & 0.08 & $0.34 * *$ & 0.14 & 0.09 \\
\hline Internal Medicine & 0.01 & 0.00 & 0.10 & 0.07 & 0.03 & 0.10 & 0.07 & 0.02 & 0.09 & 0.06 & 0.02 & 0.10 \\
\hline Internal Specialization & $-0.20 *$ & -0.08 & 0.08 & 0.01 & 0.00 & 0.08 & $-0.17 *$ & -0.07 & 0.08 & 0.00 & 0.00 & 0.08 \\
\hline OB & -0.06 & -0.02 & 0.11 & $0.19+$ & 0.05 & 0.10 & -0.04 & -0.01 & 0.11 & $0.19+$ & 0.05 & 0.10 \\
\hline Pediatrics & -0.17 & -0.05 & 0.11 & 0.01 & 0.00 & 0.11 & $-0.19+$ & -0.05 & 0.11 & 0.01 & 0.00 & 0.11 \\
\hline Psychiatry & 0.02 & 0.01 & 0.11 & $-0.20+$ & -0.06 & 0.10 & 0.04 & 0.01 & 0.10 & $-0.20 *$ & -0.06 & 0.10 \\
\hline Surgery & -0.06 & -0.02 & 0.12 & 0.10 & 0.03 & 0.11 & -0.08 & -0.02 & 0.11 & 0.11 & 0.04 & 0.11 \\
\hline Pediatrics Specialty & -0.17 & -0.04 & 0.12 & -0.07 & -0.02 & 0.12 & -0.12 & -0.03 & 0.11 & -0.08 & -0.02 & 0.12 \\
\hline South & $0.09+$ & 0.05 & 0.05 & -0.01 & -0.01 & 0.05 & 0.08 & 0.04 & 0.05 & -0.01 & -0.01 & 0.05 \\
\hline \multicolumn{13}{|l|}{ Barriers to Inclusion $^{c}$} \\
\hline General Discomfort & - & - & - & $0.49 * *$ & 0.23 & 0.07 & - & - & - & $0.48 * *$ & 0.22 & 0.07 \\
\hline Lack of knowledge/Training & - & - & - & -0.02 & -0.01 & 0.06 & - & - & - & -0.03 & -0.01 & 0.06 \\
\hline Concerned about Offending & - & - & - & $0.20 * *$ & 0.11 & 0.05 & - & - & - & $0.21 * *$ & 0.11 & 0.05 \\
\hline Colleagues may Disapprove & - & - & - & -0.09 & -0.02 & 0.12 & - & - & - & -0.08 & -0.02 & 0.12 \\
\hline Other & - & - & - & -0.11 & -0.02 & 0.30 & - & - & - & -0.11 & -0.01 & 0.30 \\
\hline \multicolumn{13}{|l|}{$R^{2}$} \\
\hline Religion Impacts Health & \multicolumn{6}{|c|}{0.326} & \multicolumn{6}{|c|}{0.382} \\
\hline Change Subject & \multicolumn{6}{|c|}{0.231} & \multicolumn{6}{|c|}{0.237} \\
\hline CFI & \multicolumn{6}{|c|}{0.978} & \multicolumn{6}{|c|}{0.989} \\
\hline TLI & \multicolumn{6}{|c|}{0.764} & & & & & & \\
\hline RMSEA (95\% CIs) & & 0.0 & $46(0$. & $5-0.068)$ & & & & & $034(0$. & $1-0.058)$ & & \\
\hline SRMR & & & & & & & & & & & & \\
\hline
\end{tabular}

Source: Religion and Spirituality in Medicine: Physicians' Perspectives; $n=1142 ; \mathrm{p}<.01 * * ; \mathrm{p}<.05 * ; \mathrm{p}<.1+$ (two-tailed tests); ${ }^{\text {a }}$ RAS is the comparison category; ${ }^{\mathrm{b}}$ Family practice is the comparison category; ${ }^{\mathrm{c}}$ Lack of time is comparison category. 
Table 6: How often Physicians Encourage Patients' Religious or Spiritual Beliefs

\begin{tabular}{|c|c|c|c|c|c|c|c|c|c|c|c|c|}
\hline & \multicolumn{6}{|c|}{ Model 1} & \multicolumn{6}{|c|}{ Model 2} \\
\hline & \multicolumn{3}{|c|}{$\begin{array}{c}\text { Direct Effects on } \\
\text { Relig. Impacts Health }\end{array}$} & \multicolumn{3}{|c|}{$\begin{array}{c}\text { Direct Effects on } \\
\text { Encourage Patients }\end{array}$} & \multicolumn{3}{|c|}{$\begin{array}{c}\text { Direct Effects on } \\
\text { Relig. Impacts Health }\end{array}$} & \multicolumn{3}{|c|}{$\begin{array}{c}\text { Direct Effects on } \\
\text { Encourage Patients }\end{array}$} \\
\hline & $b$ & $\beta$ & $\mathrm{SE}$ & $b$ & $\beta$ & $\mathrm{SE}$ & $b$ & $\beta$ & $\mathrm{SE}$ & $b$ & $\beta$ & SE \\
\hline \multicolumn{13}{|l|}{$\mathrm{R} / \mathrm{S}$ Orientations } \\
\hline $\mathrm{SBNR}^{\mathrm{a}}$ & $-0.18 *$ & -0.07 & 0.08 & 0.00 & 0.00 & 0.09 & 0.05 & 0.02 & 0.08 & 0.06 & 0.03 & 0.09 \\
\hline $\mathrm{RBNS}^{\mathrm{a}}$ & $-0.57 * *$ & -0.12 & 0.12 & -0.07 & -0.01 & 0.16 & $-0.44 * *$ & -0.09 & 0.12 & -0.05 & -0.01 & 0.17 \\
\hline NROS $^{\mathrm{a}}$ & $-0.82 * *$ & -0.34 & 0.09 & $-0.22 *$ & -0.10 & 0.11 & $-0.49 * *$ & -0.21 & 0.09 & -0.16 & -0.07 & 0.12 \\
\hline Religion Impacts Health & - & - & - & $0.15 * *$ & 0.15 & 0.04 & - & - & - & $0.13 * *$ & 0.13 & 0.04 \\
\hline \multicolumn{13}{|l|}{ Religious Affiliation } \\
\hline None & $-0.22 *$ & -0.07 & 0.11 & $-0.21+$ & -0.07 & 0.13 & -0.05 & -0.01 & 0.10 & -0.17 & -0.05 & 0.13 \\
\hline Jewish & $-0.29 * *$ & -0.11 & 0.08 & 0.06 & 0.02 & 0.09 & -0.12 & -0.05 & 0.08 & 0.10 & 0.04 & 0.09 \\
\hline Catholic & $-0.22 * *$ & -0.09 & 0.07 & 0.10 & 0.04 & 0.08 & $-0.15 *$ & -0.06 & 0.06 & 0.11 & 0.05 & 0.08 \\
\hline Other & -0.05 & -0.02 & 0.08 & 0.06 & 0.02 & 0.09 & -0.03 & -0.01 & 0.08 & 0.06 & 0.02 & 0.09 \\
\hline Spiritual Experience & $0.32 * *$ & 0.10 & 0.07 & 0.05 & 0.02 & 0.08 & $0.25 * *$ & 0.08 & 0.06 & 0.04 & 0.01 & 0.08 \\
\hline Attendance & $0.07 * *$ & 0.16 & 0.02 & 0.00 & 0.00 & 0.02 & 0.01 & 0.02 & 0.02 & -0.02 & -0.04 & 0.02 \\
\hline Internal Religiosity & - & - & - & - & - & - & $0.08 * *$ & 0.14 & 0.02 & 0.01 & 0.01 & 0.03 \\
\hline Religious Coping & - & - & - & - & - & - & $0.25 * *$ & 0.29 & 0.04 & $0.09 *$ & 0.11 & 0.04 \\
\hline Training & 0.08 & 0.04 & 0.06 & 0.04 & 0.02 & 0.07 & 0.04 & 0.02 & 0.06 & 0.04 & 0.02 & 0.07 \\
\hline Religious Area & - & - & - & $0.00 *$ & -0.07 & 0.00 & - & - & - & $0.00 *$ & -0.07 & 0.00 \\
\hline White & -0.03 & -0.01 & 0.07 & 0.08 & 0.04 & 0.08 & 0.03 & 0.01 & 0.07 & 0.11 & 0.05 & 0.08 \\
\hline Male & $-0.16 * *$ & -0.07 & 0.06 & 0.08 & 0.04 & 0.07 & $-0.09+$ & -0.04 & 0.06 & 0.09 & 0.04 & 0.07 \\
\hline Academic Setting & -0.02 & -0.01 & 0.05 & 0.04 & 0.02 & 0.06 & -0.01 & 0.00 & 0.05 & 0.04 & 0.02 & 0.06 \\
\hline Faith Based Practice & 0.04 & 0.01 & 0.07 & 0.02 & 0.01 & 0.09 & 0.02 & 0.01 & 0.07 & 0.02 & 0.01 & 0.09 \\
\hline Resident & $-0.74 * *$ & -0.08 & 0.22 & 0.37 & 0.04 & 0.23 & $-0.65 * *$ & -0.07 & 0.24 & 0.37 & 0.04 & 0.23 \\
\hline Board Certification & $-0.23 * *$ & -0.08 & 0.08 & $0.20 *$ & 0.07 & 0.09 & $-0.16 *$ & -0.06 & 0.07 & $0.22 *$ & 0.08 & 0.09 \\
\hline Age & 0.00 & -0.03 & 0.00 & 0.00 & 0.00 & 0.00 & 0.00 & -0.02 & 0.00 & 0.00 & 0.00 & 0.00 \\
\hline \multicolumn{13}{|l|}{ Physician Specialty } \\
\hline Other & -0.06 & -0.02 & 0.08 & $-0.29 * *$ & -0.12 & 0.11 & -0.04 & -0.02 & 0.08 & $-0.29 * *$ & -0.12 & 0.11 \\
\hline Internal Medicine & 0.01 & 0.00 & 0.10 & -0.01 & 0.00 & 0.10 & 0.07 & 0.02 & 0.09 & 0.00 & 0.00 & 0.10 \\
\hline Internal Specialization & $-0.20 *$ & -0.08 & 0.08 & 0.00 & 0.00 & 0.09 & $-0.17 *$ & -0.07 & 0.08 & 0.00 & 0.00 & 0.09 \\
\hline $\mathrm{OB}$ & -0.06 & -0.02 & 0.11 & -0.12 & -0.03 & 0.11 & -0.04 & -0.01 & 0.11 & -0.12 & -0.03 & 0.11 \\
\hline Pediatrics & -0.17 & -0.05 & 0.11 & $-0.25+$ & -0.07 & 0.13 & $-0.19+$ & -0.05 & 0.11 & $-0.26+$ & -0.07 & 0.14 \\
\hline Psychiatry & 0.02 & 0.01 & 0.11 & 0.07 & 0.02 & 0.11 & 0.04 & 0.01 & 0.10 & 0.08 & 0.02 & 0.11 \\
\hline Surgery & -0.07 & -0.02 & 0.12 & -0.15 & -0.04 & 0.13 & -0.08 & -0.02 & 0.11 & -0.16 & -0.05 & 0.13 \\
\hline Pediatrics Specialty & -0.18 & -0.04 & 0.12 & -0.02 & -0.01 & 0.12 & -0.12 & -0.03 & 0.11 & -0.02 & -0.01 & 0.12 \\
\hline South & $0.09+$ & 0.05 & 0.05 & 0.07 & 0.04 & 0.06 & 0.08 & 0.04 & 0.05 & 0.07 & 0.03 & 0.06 \\
\hline \multicolumn{13}{|l|}{ Barriers to Inclusion $^{c}$} \\
\hline General Discomfort & - & - & - & $-0.19 *$ & -0.08 & 0.08 & - & - & - & $-0.18 *$ & -0.08 & 0.08 \\
\hline Lack of knowledge/Training & - & - & - & -0.05 & -0.02 & 0.07 & - & - & - & -0.05 & -0.02 & 0.07 \\
\hline Concerned about Offending & - & - & - & $0.12 *$ & 0.06 & 0.06 & - & - & - & $0.11+$ & 0.06 & 0.06 \\
\hline Colleagues may Disapprove & - & - & - & -0.23 & -0.05 & 0.15 & - & - & - & $-0.25+$ & -0.05 & 0.15 \\
\hline Other & - & - & - & -0.42 & -0.05 & 0.38 & - & - & - & -0.40 & -0.05 & 0.39 \\
\hline \multicolumn{13}{|l|}{$R^{2}$} \\
\hline Religion Impacts Health & \multicolumn{6}{|c|}{0.326} & \multicolumn{6}{|c|}{0.383} \\
\hline Encourage Patients & \multicolumn{6}{|c|}{0.123} & \multicolumn{6}{|c|}{0.129} \\
\hline CFI & \multicolumn{6}{|c|}{0.971} & \multicolumn{6}{|c|}{0.986} \\
\hline TLI & \multicolumn{6}{|c|}{0.683} & & & & & & \\
\hline RMSEA (95\% CIs) & & & $47(0.0$ & 7 - 0.069) & & & & 0.0 & $35(0 . c$ & $2-0.058)$ & & \\
\hline SRMR & & & 0. & & & & & & & & & \\
\hline
\end{tabular}

Source: Religion and Spirituality in Medicine: Physicians' Perspectives; $n=1142 ; \mathrm{p}<.01 * * ; \mathrm{p}<.05 * ; \mathrm{p}<.1+$ (two-tailed tests); ${ }^{\text {a }}$ RAS is the comparison category; ${ }^{\mathrm{b}}$ Family practice is the comparison category; ${ }^{\mathrm{c}}$ Lack of time is comparison category. 


\begin{tabular}{|c|c|c|c|c|c|c|c|c|c|c|c|c|}
\hline & \multicolumn{6}{|c|}{ Model 1} & \multicolumn{6}{|c|}{ Model 2} \\
\hline & \multicolumn{3}{|c|}{$\begin{array}{l}\text { Direct Effects on } \\
\text { Relig. Impacts }\end{array}$} & \multicolumn{3}{|c|}{$\begin{array}{l}\text { Direct Effects on } \\
\text { Praying }\end{array}$} & \multicolumn{3}{|c|}{$\begin{array}{l}\text { Direct Effects on } \\
\text { Relig. Impacts }\end{array}$} & \multicolumn{3}{|c|}{$\begin{array}{l}\text { Direct Effects on } \\
\text { Praying }\end{array}$} \\
\hline & $b$ & $\beta$ & SE & $b$ & $\beta$ & SE & $b$ & $\beta$ & SE & $b$ & $\beta$ & $\mathrm{SE}$ \\
\hline \multicolumn{13}{|l|}{ R/S Orientations } \\
\hline $\mathrm{SBNR}^{\mathrm{a}}$ & $-0.18 *$ & -0.07 & 0.08 & $-0.12+$ & -0.06 & 0.07 & 0.05 & 0.02 & 0.08 & -0.03 & -0.01 & 0.07 \\
\hline $\mathrm{RBNS}^{\mathrm{a}}$ & $-0.58 * *$ & -0.12 & 0.12 & -0.15 & -0.03 & 0.11 & $-0.44 * *$ & -0.09 & 0.12 & -0.12 & -0.03 & 0.11 \\
\hline NROS $^{\mathrm{a}}$ & $-0.82 * *$ & -0.34 & 0.09 & -0.07 & -0.03 & 0.08 & $-0.49 * *$ & -0.21 & 0.09 & 0.04 & 0.02 & 0.08 \\
\hline Religion Impacts Health & - & - & - & $0.16 * *$ & 0.18 & 0.03 & - & - & - & $0.12 * *$ & 0.14 & 0.03 \\
\hline \multicolumn{13}{|l|}{ Religious Affiliation } \\
\hline None & $-0.22 *$ & -0.07 & 0.11 & $-0.30 * *$ & -0.11 & 0.08 & -0.05 & -0.01 & 0.10 & $-0.24 * *$ & -0.08 & 0.08 \\
\hline Jewish & $-0.3 * *$ & -0.11 & 0.08 & $-0.40 * *$ & -0.17 & 0.06 & -0.13 & -0.05 & 0.08 & $-0.34 * *$ & -0.15 & 0.06 \\
\hline Catholic & $-0.22 * *$ & -0.09 & 0.07 & $-0.21 * *$ & -0.10 & 0.07 & $-0.15 *$ & -0.07 & 0.06 & $-0.18 * *$ & -0.09 & 0.07 \\
\hline Other & -0.05 & -0.02 & 0.08 & -0.05 & -0.02 & 0.08 & -0.03 & -0.01 & 0.08 & -0.03 & -0.02 & 0.07 \\
\hline Spiritual Experience & $0.32 * *$ & 0.10 & 0.07 & $0.25 * *$ & 0.09 & 0.08 & $0.25 * *$ & 0.08 & 0.06 & $0.24 * *$ & 0.09 & 0.08 \\
\hline Attendance & $0.07 * *$ & 0.16 & 0.02 & $0.04 * *$ & 0.12 & 0.01 & 0.01 & 0.02 & 0.02 & 0.02 & 0.06 & 0.01 \\
\hline Internal Religiosity & - & - & - & - & - & - & $0.08 * *$ & 0.14 & 0.02 & 0.02 & 0.03 & 0.02 \\
\hline Religious Coping & - & - & - & - & - & - & $0.25 * *$ & 0.29 & 0.04 & $0.14 * *$ & 0.18 & 0.03 \\
\hline Training & 0.08 & 0.04 & 0.06 & $0.32 * *$ & 0.16 & 0.06 & 0.04 & 0.02 & 0.06 & $0.30 * *$ & 0.15 & 0.06 \\
\hline Religious Area & - & - & - & 0.00 & 0.02 & 0.00 & - & - & - & 0.00 & 0.02 & 0.00 \\
\hline White & -0.03 & -0.01 & 0.07 & $-0.14+$ & -0.06 & 0.07 & 0.04 & 0.02 & 0.07 & -0.10 & -0.05 & 0.07 \\
\hline Male & $-0.16 * *$ & -0.07 & 0.06 & -0.04 & -0.02 & 0.05 & $-0.09+$ & -0.04 & 0.06 & -0.02 & -0.01 & 0.05 \\
\hline Academic Setting & -0.02 & -0.01 & 0.05 & 0.02 & 0.01 & 0.05 & -0.01 & 0.00 & 0.05 & 0.02 & 0.01 & 0.05 \\
\hline Faith Based Practice & 0.04 & 0.01 & 0.07 & -0.02 & -0.01 & 0.06 & 0.02 & 0.01 & 0.07 & -0.03 & -0.01 & 0.06 \\
\hline Resident & $-0.74 * *$ & -0.08 & 0.22 & 0.27 & 0.03 & 0.29 & $-0.65 * *$ & -0.07 & 0.24 & 0.27 & 0.03 & 0.28 \\
\hline Board Certification & $-0.23 * *$ & -0.08 & 0.08 & $-0.12+$ & -0.05 & 0.07 & $-0.16 *$ & -0.06 & 0.07 & -0.10 & -0.04 & 0.07 \\
\hline Age & 0.00 & -0.03 & 0.00 & 0.00 & -0.03 & 0.00 & 0.00 & -0.02 & 0.00 & 0.00 & -0.03 & 0.00 \\
\hline \multicolumn{13}{|l|}{ Physician Specialty ${ }^{\mathrm{b}}$} \\
\hline Other & -0.06 & -0.02 & 0.08 & -0.04 & -0.02 & 0.09 & -0.04 & -0.02 & 0.08 & -0.04 & -0.02 & 0.09 \\
\hline Internal Medicine & 0.01 & 0.00 & 0.10 & $-0.24 * *$ & -0.09 & 0.09 & 0.07 & 0.02 & 0.09 & $-0.22 *$ & -0.08 & 0.09 \\
\hline Internal Specialization & $-0.20 *$ & -0.08 & 0.08 & -0.12 & -0.06 & 0.08 & $-0.17 *$ & -0.07 & 0.08 & -0.12 & -0.06 & 0.08 \\
\hline OB & -0.06 & -0.02 & 0.11 & 0.07 & 0.02 & 0.11 & -0.04 & -0.01 & 0.11 & 0.08 & 0.02 & 0.11 \\
\hline Pediatrics & -0.17 & -0.05 & 0.11 & $-0.17+$ & -0.05 & 0.10 & $-0.18+$ & -0.05 & 0.11 & $-0.18+$ & -0.06 & 0.10 \\
\hline Psychiatry & 0.02 & 0.01 & 0.11 & $-0.38 * *$ & -0.12 & 0.09 & 0.04 & 0.01 & 0.10 & $-0.37 * *$ & -0.12 & 0.09 \\
\hline Surgery & -0.07 & -0.02 & 0.12 & 0.03 & 0.01 & 0.10 & -0.08 & -0.02 & 0.11 & 0.02 & 0.01 & 0.09 \\
\hline Pediatrics Specialty & -0.18 & -0.04 & 0.12 & 0.09 & 0.02 & 0.14 & -0.12 & -0.03 & 0.11 & 0.10 & 0.03 & 0.13 \\
\hline South & $0.09+$ & 0.05 & 0.05 & 0.05 & 0.03 & 0.05 & 0.08 & 0.04 & 0.05 & 0.04 & 0.02 & 0.05 \\
\hline \multicolumn{13}{|l|}{ Barriers to Inclusion ${ }^{\mathrm{c}}$} \\
\hline General Discomfort & - & - & - & $-0.2 * *$ & -0.09 & 0.05 & - & - & - & $-0.18 * *$ & -0.08 & 0.05 \\
\hline Lack of knowledge/Training & - & - & - & -0.02 & -0.01 & 0.05 & - & - & - & -0.01 & -0.01 & 0.05 \\
\hline Concerned about Offending & - & - & - & 0.01 & 0.01 & 0.05 & - & - & - & 0.00 & 0.00 & 0.05 \\
\hline Colleagues may Disapprove & - & - & - & $-0.20+$ & -0.05 & 0.12 & - & - & - & $-0.23 *$ & -0.05 & 0.12 \\
\hline Other & - & - & - & $-0.61 * *$ & -0.09 & 0.12 & - & - & - & $-0.59 * *$ & -0.08 & 0.12 \\
\hline \multicolumn{13}{|l|}{$R^{2}$} \\
\hline Religion Impacts Health & \multicolumn{6}{|c|}{0.326} & \multicolumn{6}{|c|}{0.382} \\
\hline Pray with Patients & \multicolumn{6}{|c|}{0.311} & \multicolumn{6}{|c|}{0.327} \\
\hline CFI & \multicolumn{6}{|c|}{0.982} & \multicolumn{6}{|c|}{0.991} \\
\hline TLI & \multicolumn{6}{|c|}{0.8} & & & & & & \\
\hline RMSEA (95\% CIs) & & 0.0 & $47(0.0$ & $26-0.069)$ & & & & 0 . & $34(0.0$ & $1-0.058)$ & & \\
\hline SRMR & & & & & & & & & & & & \\
\hline
\end{tabular}

Source : Religion and Spirituality in Medicine: Physicians' Perspectives; $n=1142 ; \mathrm{p}<.01 * * ; \mathrm{p}<.05 * ; \mathrm{p}<.1+\left(\right.$ two-tailed tests); ${ }^{\text {a }}$ RAS is the comparison category; ${ }^{\mathrm{b}}$ Family practice is the comparison category; ${ }^{\mathrm{c}}$ Lack of time is comparison category. 